Metallurgical Transactions B, 1999, vol. 30B (4), pp. 639-654

\title{
MODELING OF INCLUSION REMOVAL IN A TUNDISH
}

\author{
Yuji Miki and Brian G. Thomas ${ }^{\dagger}$
}

\begin{abstract}
Mathematical models have been developed to predict the removal of alumina inclusions from molten steel in a continuous casting tundish, including the effects of turbulent collisions, reoxidation, flotation, and removal on the inclusion size distribution. The trajectories of inclusion particles are tracked through the three-dimensional (3-D) flow distribution, which was calculated with the K- $\varepsilon$ turbulence model and includes thermal buoyancy forces based on the coupled temperature distribution. The predicted distributions are most consistent with measurements if reoxidation is assumed to increase the number of small inclusions, collision agglomeration is accounted for, and inclusion removal rates are based on particle trajectories tracked through a non-isothermal 3-D flow pattern including Stokes flotation based on a cluster density of $5,000 \mathrm{~kg} / \mathrm{m}^{3}$, and random motion due to turbulence. Steel samples should be taken from as deep as possible in the tundish near the outlet and several residence times after the ladle is opened, in order to best measure the $\mathrm{Al}_{2} \mathrm{O}_{3}$ concentration entering the submerged entry nozzle to the mold. Inclusion removal rates vary greatly with size and with the presence of a protective slag cover to prevent reoxidation. The random motion of inclusions due to turbulence improves the relatively slow flotation of small inclusions to the top surface flux layer. However, it also promotes collisions, which slows down the relatively fast net removal rates of large inclusions. For the conditions modeled, the flow pattern reaches steady state soon after a new ladle opens, but the temperature and inclusion distributions continue to evolve even after 1.3 residence times. The removal of inclusions does not appear to depend on the tundish aspect ratio for the conditions and assumptions modeled. It is hoped that this work will inspire future measurements and the development of more comprehensive models of inclusion removal. These validated models should serve as powerful quantitative tools to predict and optimize inclusion removal during molten steel processing, leading to higher quality steel.
\end{abstract}


Metallurgical Transactions B, 1999, vol. 30B (4), pp. 639-654

$\dagger$ Yuji Miki, formerly a Visiting Researcher with the Department of Mechanical and Industrial Engineering, University of Illinois, Urbana, IL, is currently a Senior Researcher in the Steelmaking Research Laboratory at Kawasaki Steel, 1 Mizushima-Kawasaki-dori Kurashiki-shi, 712 Japan (email: miki@giken.kawasaki-steel.co.jp)

Dr. Brian G. Thomas is a Professor with the Department of Mechanical and Industrial Engineering at the University of Illinois at Urbana-Champaign, 1206 West Green Street, Urbana, IL, 61801 (email: bgthomas@uiuc.edu 


\section{INTRODUCTION}

The tundish is important for regulating the flow of molten steel from individual ladles to the continuous casting mold. Ideally, it is also used as a metallurgical vessel to aid in inclusion removal and improve the quality of the cast steel product. Inclusion removal in a tundish is controlled by many factors, including the fluid flow pattern, inclusion agglomeration and flotation, and top surface condition, where inclusions may be either removed or generated, depending on the slag composition and reoxidation conditions. Furthermore, unsteady flow phenomena, such as occur during a ladle exchange, are important to inclusion removal and quality ${ }^{[1]}$.

Several previous numerical simulations have investigated flow and inclusion behavior in tundishes. Tacke and Ludwig ${ }^{[2]}$ and Kaufmann et. al. ${ }^{[3]}$ studied inclusion flotation based on scalar diffusion through an isothermal 3-D turbulent flow field. H. Tozawa et. al. ${ }^{[4]}$ and A. K. Sinha et al. ${ }^{[5]}$ have developed models to simulate inclusion flotation in a tundish which account for inclusion coalescence. Heat transfer must be taken into account when determining the flow pattern because there are important temperature differences between the hot steel incoming from the ladle and the colder steel remaining in the tundish ${ }^{[6]}$. Y.Sahai et. $\mathrm{al}^{[7,8]}$ studied the transient flow and temperature distribution in a tundish and found great differences between steady and unsteady state. Natural convection was found to reverse the direction of flow relative to isothermal conditions. Barreto et. $\mathrm{al}^{[9]}$ also suggested that convection changes the flow in a tundish. The corresponding effect of transient thermal-flow conditions on the inclusion distribution has received less study.

In this work, computational models are developed to simulate unsteady flow, temperature and $\mathrm{Al}_{2} \mathrm{O}_{3}$ concentration in a tundish after a ladle exchange. These models were applied previously to investigate inclusion removal from an RH Degasser. ${ }^{[10]}$ The predicted distributions are compared here with 
measurements in an operating tundish and with calculations in steady state. The models are applied to investigate the relative importance of various phenomena on inclusion removal.

\section{MODEL DESCRIPTION}

Three-dimensional (3-D) flow of molten steel and temperature evolution in a tundish is simulated in both steady and transient conditions using the standard K- $\varepsilon$ turbulence model for high Reynold's number

flows in the computational-fluid-dynamics code, FLUENT ${ }^{[11]}$. The corresponding inclusion behavior is investigated using three separate models. First, inclusion particle trajectories are calculated through the flow field. Second, evolution of the inclusion size distribution due to collisions and flotation was modeled for the average flow and turbulence conditions in the tundish. Finally, time evolution of a general inclusion concentration field was calculated using a scalar diffusion model.

\section{A. Fluid flow and heat transfer model.}

All three inclusion models utilize results from a 3-D continuum transport model of flow and heat transfer. This model solves the following incompressible mass conservation equation and three momentum balance equations for the velocities, $\mathrm{u}_{\mathrm{i}}$, and pressure, $\mathrm{P}$, throughout the 3-D domain of the tundish.

$$
\begin{aligned}
& \frac{\partial u_{i}}{\partial x_{i}}=0 \\
& \frac{\partial}{\partial t} \rho u_{j}+\frac{\partial}{\partial x_{i}} \rho u_{i} u_{j}=-\frac{\partial P}{\partial x_{i}}+\frac{\partial}{\partial x_{i}} \mu_{e f f}\left(\frac{\partial u_{i}}{\partial x_{j}}+\frac{\partial u_{j}}{\partial x_{i}}\right)+\alpha\left(T_{0}-T\right) \rho_{0} g_{j} \\
& \quad \text { where } \mu_{e f f}=\mu_{0}+\mu_{t}=\mu_{0}+\rho C_{\mu} \frac{k^{2}}{\varepsilon}
\end{aligned}
$$

Here, $\mathrm{i}$ and $\mathrm{j}$ each represent the 3 coordinate directions, $(\mathrm{x}, \mathrm{y}, \mathrm{z})$ and repeated indices imply summation. All symbols are defined in a Nomenclature section at the end of this paper. The effective viscosity, $\mu_{\mathrm{eff}}$, depends mainly on the turbulence parameters $K$ and $\varepsilon$, found by solving two further 
transport equations. ${ }^{[1]}$ The effect of thermal convection on the flow is accounted for with the Boussinesq approximation $^{[11]}$, which accounts for thermal buoyancy forces via the last term in Eq. [2].

The heat-transfer model solves a 3-D energy transport equation,

$$
\frac{\partial}{\partial t}(\rho h)+\frac{\partial}{\partial x_{i}}\left(\rho u_{i} h\right)=-\frac{\partial}{\partial x_{i}}\left(k_{e f f}\right) \frac{\partial T}{\partial x_{i}}
$$

where $h$ is enthalpy, and $k_{\text {eff }}$ is the effective thermal conductivity, controlled mainly by the turbulence level:

$$
k_{e f f}=k_{0}+\frac{C_{p} \mu_{t}}{\operatorname{Pr}_{t}}
$$

Figure 1 shows the geometry of a typical tundish modeled in this work. Due to symmetry, only a $1 / 2$ longitudinal section was modeled. At the inlet, velocity is fixed at $0.43 \mathrm{~m} / \mathrm{sec}$, turbulent kinetic energy at $0.003 \mathrm{~m}^{2} / \mathrm{s}^{2}$ and turbulence dissipation rate at $0.0003 \mathrm{~m}^{2} / \mathrm{s}^{3}$. The boundary condition over the outlet plane is the standard condition of zero gradient for velocity, pressure and temperature. The inlet and outlet openings are crudely approximated as rectangular planes of $0.1 * 0.05 \mathrm{~m}^{2}$. The dam hole size is $0.3 * 0.3$ $\mathrm{m}$. The top surface is a shear-stress free (symmetry) plane. Standard wall laws, based on the highReynold's number turbulence model of Launder and Spalding, are employed on all other surfaces. ${ }^{[11]}$

Thermal boundary conditions are fixed heat fluxes, taken from Y.Sahai et al. ${ }^{[7]}: 15 \mathrm{~kW} \mathrm{~m}$ from the top surface, $1.4 \mathrm{~kW} \mathrm{~m}^{-2}$ from the bottom surface, $3.2 \mathrm{~kW} \mathrm{~m}^{-2}$ from the longitudinal vertical wall, $3.8 \mathrm{~kW} \mathrm{~m}^{-2}$ from the transverse vertical end wall, and $1.75 \mathrm{~kW} \mathrm{~m}^{-2}$ from the walls of the internal dam.

Table 1 shows the molten steel properties and operating conditions modeled. To achieve convergence in FLUENT using the SIMPLE algorithm, under-relaxation factors of 0.15 were chosen for the velocity iterations, 0.7 for pressure, 0.15 for $\mathrm{K}$ and $\varepsilon$, and 0.8 for enthalpy and $\mathrm{Al}_{2} \mathrm{O}_{3}$ concentration. The steady- 
state coupled 3-D flow model required 3,000 iterations to converge and about 1,000 sec of CPU time on a single processor of the Silicon Graphics Inc. Power Challenge Array at the National Center for Supercomputing Applications at the University of Illinois. Transient calculations required about 10,000 sec of computer time to simulate 200 seconds of flow.

\section{B. Inclusion removal model with trajectory calculation}

Inclusion trajectories were calculated using a Lagrangian particle tracking method, which solves a transport equation for each inclusion as it travels through the previously-calculated constant molten-steel flow field. The mean local inclusion velocity components, $\bar{u}_{c i}$, needed to obtain the particle path, are obtained from the following force balance, which includes drag and buoyancy forces relative to the steel:

$$
\begin{aligned}
& \frac{d \bar{u}_{c i}}{d t}=F_{D}\left(u_{i}-\bar{u}_{c i}\right)+\frac{\left(\rho_{c}-\rho\right)}{\rho_{c}} g_{i} \\
& F_{D}=\frac{18 \mu_{o} C_{D} \operatorname{Re}}{24 \rho_{c} D_{c}^{2}}
\end{aligned}
$$

To simulate the chaotic effect of the turbulent eddies on the particle paths, a discrete random walk model is applied during most inclusion trajectory calculations. In this model, a random velocity vector, $u_{c i}^{\prime}$, is added to the calculated time-averaged vector, $\bar{u}_{c i}$, to obtain the inclusion velocity $\mathrm{u}_{\mathrm{ci}}$ at each time step as it travels through the fluid. Each random component of the inclusion velocity is proportional to the local turbulent kinetic energy level, $\mathrm{K}$ according to Eq.[7].

$$
u_{c i}^{\prime}=\zeta_{i} \sqrt{\overline{u_{i}^{\prime 2}}}=\zeta_{i} \sqrt{\frac{2 K}{3}}
$$

where $\zeta_{\mathrm{i}}$ is a random number, normally distributed between -1 and 1 that changes at each time step.

Inclusions are injected computationally at many different locations distributed homogeneously over the inlet plane. Each trajectory is calculated through the constant steel flow field until the inclusion either is trapped on the top surface or exits the tundish outlet. Inclusions touching a side wall are assumed to 
reflect. This assumption should be investigated with further work, as inclusions might alternatively stick to walls. Statistics were gathered to quantify the fates of 100-1,000 inclusion trajectories for each particle size.

Inclusion density and size are important to its flotation, and are controlled by the nature of the cluster. For trajectory and collision calculations, the radius of an $\mathrm{Al}_{2} \mathrm{O}_{3}$ cluster was considered to be that of the circumambient sphere. Tozawa et al. ${ }^{[4]}$ used fractal theory to relate the measured diameter of an inclusion cluster, $\mathrm{D}_{\mathrm{c}}$, with the number of small solid alumina particles (with diameter $\mathrm{d}$ ) in each cluster.

$$
N=d^{-1.8} D_{c}^{1.8}
$$

The number of small particles making up the cluster, $\mathrm{N}$, is related to the radius, $\mathrm{R}_{\mathrm{m}}$, of an equivalent solid sphere with the same mass as the cluster via:

$$
\mathrm{R}_{\mathrm{m}}{ }^{3}=\mathrm{N}(\mathrm{d} / 2)^{3}
$$

The diameter of the circumambient sphere of a cluster, $\mathrm{D}_{\mathrm{c}}$ is calculated from the measured values of $\mathrm{d}$ and $\mathrm{R}_{\mathrm{m}}$ using Eq.[10], which combines Eqs. [8] and [9].

$$
D_{c}=2 R_{c}=2^{5 / 3} R_{m}^{5 / 3} d^{-2 / 3}
$$

As shown in Figure 2, the resulting cluster diameter is much larger and its density is much closer to liquid steel than it is to the corresponding solid alumina sphere, whose radius is found through laser diffraction scattering measurements described in Section 3.

The cluster density may be estimated knowing the volume fraction of $\mathrm{Al}_{2} \mathrm{O}_{3}$ in the cluster, $\beta .^{[12]}$

$$
\rho_{c}=(1-\beta) \rho+\beta \rho_{\mathrm{Al}_{2} \mathrm{O}_{3}}
$$

Asano et al. ${ }^{[12]}$ measured the volume fraction of $\mathrm{Al}_{2} \mathrm{O}_{3}$ in agglomerated inclusion clusters to be about 0.03. When $\beta$ is set to 0.03 in Eq.[11], the cluster density is almost the same as that of steel, so there is little driving force for flotation, even for a large cluster. This corresponds with CASE 1 in Figure 2, and produces flotation velocities which are believed to be smaller than occur in a real tundish. On the other 
hand, the flotation velocity of an equivalent mass sphere of solid $\mathrm{Al}_{2} \mathrm{O}_{3}, \mathrm{CASE} 3$ of Figure 2, is larger than that of an actual cluster. The true velocity is believed to be intermediate between CASE 1 and CASE 3 . According to Beckermann, only some of the liquid steel in the circumambient sphere moves at the cluster velocity $^{[13]}$. Furthermore, the rough surface of the cluster likely does not significantly increase the drag, $\mathrm{F}_{\mathrm{D}}{ }^{[14]}$ Thus, the true average density of the cluster is believed to be the intermediate CASE 2 in Figure 2. Its value is found in this study by calibration of the model with experimental measurements.

\section{Lumped inclusion removal model with size evolution.}

The second inclusion removal model calculates the evolution of the inclusion size distribution for the duration of its residence time in the tundish. This model considers the collision of particles due to both turbulence and differences in flotation removal rate of each inclusion size. This is a lumped model, based on uniform average properties within the tundish. The collision rate due to turbulent eddy motion is governed by the mean turbulent dissipation level, $\varepsilon$, and the cluster size. Appendix I describes details of this size evolution model. ${ }^{[10]}$

In this work, the initial size distribution was taken from measurements in the ladle. A mean turbulent energy dissipation rate of $0.0004 \mathrm{~m}^{2} / \mathrm{s}^{3}$ was assumed, based on results of the 3-D fluid flow model using FLUENT. Similarly, the inclusion flotation removal rates needed in this lumped model, S, were evaluated for each cluster size range from the results of the many trajectories calculated with FLUENT. To include the effects of both reoxidation (via exposure to the atmosphere at the tundish surface) and continued deoxidation (due to lowering temperature etc.), inclusions of $0.5 \mu \mathrm{m}$ radius are assumed to be generated at the rate, $\mathrm{G}$, of $2.5 \times 10^{9}$ inclusions $/ \mathrm{m}^{3} / \mathrm{s}$. The influence of argon bubbles was assumed to be negligible. 


\section{Inclusion diffusion model}

The third inclusion model calculates the distribution of small inclusions using a scalar or "species" diffusion model. It solves the following equation for the time evolution of the inclusion mass fraction, C, given the steady flow velocities calculated previously.

$$
\frac{\partial}{\partial t}\left(\rho_{c} C\right)+\frac{\partial}{\partial x_{i}}\left(\rho_{c} u_{i} C\right)+\frac{\partial}{\partial x_{i}}\left(\rho_{c} D_{e f f} \frac{\partial C}{\partial x_{i}}\right)=0
$$

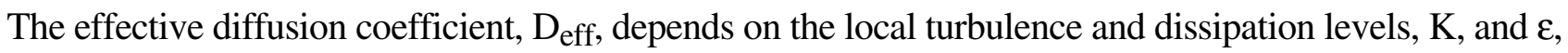
calculated previously.

$$
D_{e f f}=D_{0}+\frac{\mu_{e f f}}{\rho_{c} S c_{t}}
$$

The boundary condition of zero concentration gradient was assumed over all walls, bottom, outlet plane, the symmetry plane and the top surface. The flotation of inclusions in the bulk liquid, reoxidation, and collision agglomeration are ignored in this model, so it is used only to investigate general transient mixing behavior. Specifically, the time for the inclusion concentration to approach steady state after a large change in the ladle concentration is predicted. Inclusion concentration at the inlet is fixed at $30 \mathrm{ppm}$ $\mathrm{Al}_{2} \mathrm{O}_{3}$, while an initial guess of $15 \mathrm{ppm}$ is chosen for the entire domain of the tundish. 


\section{MEASUREMENT OF INCLUSION SIZE DISTRIBUTION}

A steel sample of $150 \mathrm{~g}$ was taken $0.5 \mathrm{~m}$ from the top of the 160 tonne ladle at the start of casting by dipping through the lid of the ladle from a crane poised overhead. Based on previous experience, the inclusions in ladle samples were not expected to change much with time. A similar sample was taken 0.5 $\mathrm{m}$ from the top of the tundish (directly above the outlet) at about 2,400 sec after the ladle opened. No slag coverage was used on either tundish chamber. Instead, a cover was put over the tundish and the cavity was filled with Argon gas. It is believed that some reoxidation was possible, however, as the seal was not perfect.

Inclusions were extracted using an acid technique to dissolve away the surrounding steel, and inclusions

size distributions were measured by a laser diffraction scattering method ${ }^{[15]}$. For each inclusion cluster, an equivalent solid sphere radius was measured. These measured size distributions were converted to equivalent cluster size distributions for use in validating the subsequent models. The diameter, $\mathrm{d}$, of the small alumina particles making up a typical cluster was estimated to be about $4 \mu \mathrm{m}$.

Figure 3 shows the measured inclusion size distributions in both ladle and tundish. The horizontal axis shows the measured equivalent radius, $\mathrm{R}_{\mathrm{m}}$, and corresponding cluster radius, $\mathrm{R}_{\mathrm{c}}$, estimated by Eq.[10]. The number of large inclusions in the tundish has decreased from that in the ladle but the number of small inclusions has increased. Figure $3 \mathrm{~b}$ ) shows the same trends reported on a mass concentration basis, which indicates the increased importance of the larger inclusions. The total mass concentration of $\mathrm{Al}_{2} \mathrm{O}_{3}$ was $23 \mathrm{ppm}$ in the ladle and $24 \mathrm{ppm}$ in the tundish. This would correspond to total oxygen contents of about $11 \mathrm{ppm}$. The dissolved oxygen content for this Al-killed steel is less than $1 \mathrm{ppm}$. 


\section{STEADY-STATE FLOW AND TEMPERATURE SIMULATIONS.}

Figures 4 and 5 show the velocity vectors calculated in the tundish using an isothermal 3-D flow model with about 18,000 nodes. Note the high velocities and turbulent recirculation and mixing in the first chamber. As steel exits the first chamber through the hole in the bottom of the dam, it flows directly along the bottom towards the exit port. There is a significant amount of "short circuiting" in the larger second chamber, as a large, relatively dead region is created in its upper portion.

Figures 6,7, and 8 show velocity vectors calculated in the tundish using the fully-coupled steady-state 3-D thermal-flow model, which includes the effect of thermal buoyancy on the flow pattern. Figure 9 shows the corresponding steel temperature distribution. The steel loses a total of about $5^{\circ} \mathrm{C}$ of superheat as it flows through this tundish. The hotter steel flowing from the first chamber beneath the dam bends upward, due to its lower density relative to the steel in the long second chamber. This temperature difference of only $2^{\circ} \mathrm{C}$ is enough to totally reverse the flow pattern in the larger chamber (relative to the isothermal case). A comparison of Figures 5 and 7 shows that the upward flow, which occurs through just the central hole in the dam, is sufficient to reverse the flow throughout the entire chamber. These results further emphasize the findings of previous researchers, who observed the same flow-reversal effect

when the opening between tundish chambers extended across the entire tundish width. ${ }^{[7,8,16]}$ This recirculating flow promotes mixing, longer plug flow time, and better inclusion removal.

Figure 10 shows the corresponding turbulent kinetic energy distribution and Figure 11 shows the turbulence dissipation rate. Both the turbulent kinetic energy and dissipation rate are the greatest just below the nozzle and are relatively very small elsewhere. Thus, mixing and agglomeration of inclusions is expected to be large in the first chamber, and negligible in the second chamber. 


\section{INCLUSION TRAJECTORIES AND REMOVAL SIMULTATIONS.}

Inclusion cluster trajectories were then calculated through these steady flow fields. Figure 12 shows a typical trajectory of a cluster with $50 \mu \mathrm{m}$ radius moving through the non-isothermal flow field in Figure 6. Figure 13 shows the trajectory of a typical inclusion injected from the same position using the random walk model. Note the complex recirculating path in the first chamber, which often traps inclusions in the top surface, followed by flotation to the top surface of the second chamber. The jagged path of the inclusions in Figure 13 is due to the random walk method to simulate turbulent motion. This has a significant influence on increasing the removal rate of small inclusions.

\section{A. Effect of thermal convection}

As thermal convection changes the flow pattern, the flotation of inclusion clusters also changes. Figure 14 compares cluster removal from the steady isothermal flow field with that from the coupled flowtemperature field (non-isothermal), based on results for 200 trajectories at each cluster size. Thermal convection clearly promotes cluster removal, especially for small size clusters, less than $10 \mu \mathrm{m}$ radius.

\section{B. Effect of random motion and density.}

The random motion of clusters greatly affects their removal rate. Figure 15 compares the calculated inclusion removal fractions with and without random motion, for densities of 4,000 kg/m and 5,000 $\mathrm{kg} / \mathrm{m}^{3}$. The fraction of inclusion clusters removed from the tundish, $\mathrm{Q}$, is defined as

$$
Q=\frac{N_{\text {in }}-N_{\text {out }}}{N_{\text {in }}}
$$

where $\mathrm{N}_{\text {in }}$ is number of inclusions mathematically injected into the ladle to tundish shroud and $\mathrm{N}_{\text {out }}$ is the number of inclusions exiting the tundish outlet.

The random motion is shown to dampen the effect of inclusion size on the removal rate by flotation. This is because the turbulent eddies in the liquid carry any inclusions near the surface in many different 
directions. This random motion greatly promotes the flotation and removal of small inclusion clusters $(<$ $30 \mu \mathrm{m})$, because it increases their otherwise slim chances of contacting the surface and being removed. However, this randomness also causes a slight decrease in the flotation and removal of large inclusions. This is partly because it disrupts the strong natural tendency of large inclusions to float. The random walk results are considered more representative of the turbulent state in a real tundish. Increasing the

inclusion flotation rate by decreasing the cluster density from $5,000 \mathrm{~kg} / \mathrm{m}^{3}$ to $4,000 \mathrm{~kg} / \mathrm{m}^{3}$ does not increase the fraction of clusters removed by very much, particularly for smaller sizes.

\section{Site of flotation removal.}

The tundish dam divides the tundish into two chambers. Figure 16 shows the calculated inclusion removal in each chamber, based on trajectories with a cluster density of $5,000 \mathrm{~kg} / \mathrm{m}^{3}$. The flotation of large inclusions in the first chamber is larger than that in the second chamber even though the residence time is smaller. This demonstrates the importance of both flow pattern and turbulence level ( $\mathrm{K}$ and $\varepsilon$ ) on inclusion removal rate.

\section{MODEL VERIFICATION.}

To evaluate the accuracy of the models, $\mathrm{Al}_{2} \mathrm{O}_{3}$ concentration predictions are compared with measurements made at the sample point. Concentration at the sample position is calculated by counting inclusions whose trajectories pass through the particular small volume in the tundish where the sample was taken. From a steady-state mass balance, Eqs. [15] and [16] estimate the number of inclusions passing normally through planes at the inlet and sample positions in an arbitrary time interval, $\Delta \mathrm{t}$.

$$
\begin{aligned}
& N_{i n}=A_{i n} V_{i n} C_{i n} \Delta t \\
& N_{s}=A_{s} V_{s} C_{s} \Delta t
\end{aligned}
$$


Combining Eqs.[15] and [16] produces the following estimate of concentration at the sample position, $\mathrm{C}_{\mathrm{s}}$, relative to the inlet concentration, $\mathrm{C}_{\mathrm{in}}$.

$$
C_{s}=\left(\frac{N_{s}}{N_{i n}}\right)\left(\frac{V_{i n}}{V_{s}}\right)\left(\frac{A_{i n}}{A_{s}}\right) C_{i n}
$$

The trajectories of 1,000 inclusions were calculated for each cluster radius using the random walk model and a cluster density of $5,000 \mathrm{~kg} / \mathrm{m}^{3}$. The number of entrapped inclusions, and the fluid velocity were found at the sample location. Then, $\mathrm{C}_{\mathrm{s}}$ and $\mathrm{Q}$ were estimated using Eq.[17] and Eq.[14]. Figure 17 compares the calculated and measured inclusion distributions at the sample position.

The calculations agree reasonably with the measurements. However, the measured number of clusters smaller than $10 \mu \mathrm{m}$ radius is more than calculated. This is surely due to the reoxidation that likely accompanied the lack of slag cover in this tundish. Reoxidation was ignored in this model, which simulates a tundish with perfect slag cover. The measured number of clusters larger than $50 \mu \mathrm{m}$ radius is also more than calculated, probably due to inclusion agglomeration from the collisions of smaller inclusions.

Figure 17 also shows that the inclusion concentration at the sample point is significantly higher than at the outlet. This reflects the fact that inclusions are continuously removed as the steel moves through the tundish. Thus, the steel leaving the tundish from this flow pattern is generally more refined than the steel elsewhere in the tundish. Note that most of the large inclusions $(>60 \mu \mathrm{m})$ float out, so their concentration is low at both the sample point and the outlet. The difference between sample point and outlet suggests that samples should be taken as deep in the tundish near the outlet as possible to be most representative of the exiting steel. 
To investigate the effect of inclusion agglomeration and reoxidation, the inclusion size evolution model ${ }^{[10]}$ was applied. Recall that this lumped model evolves the particle size distribution with time including the effects of agglomeration due to turbulence-dissipation-dependent collisions, flotation removal, and reoxidation generation. Flotation removal rates, $\mathrm{S}$, were taken from the results calculated at the outlet in Figure 17. Reoxidation was assumed to generate new inclusions only in the smallest size range. This generation is responsible for negative removal rates at small cluster radii, which was also observed in the measurements. Evolution of the size distributions were calculated by this lumped model for the mean residence time of 1060s.

Figure 18 compares the removal rates calculated from the results of the calibrated lumped model, (flotation, collision, reoxidation), with those of the random-walk inclusion-trajectory model used to produce Figure 17, which assumes $5,000 \mathrm{~kg} / \mathrm{m}^{3}$ cluster density, and constant particle size (flotation only). Both sets of calculated results agree reasonably with the measurements for all sizes. This agreement suggests that clusters contain $\mathrm{Al}_{2} \mathrm{O}_{3}$, steel and vacuum, such that the average cluster density is somewhere near $5,000 \mathrm{~kg} / \mathrm{m}^{3}$. This density could be produced, for example, when clusters embed about equal volumes of steel and $\mathrm{Al}_{2} \mathrm{O}_{3}(\beta=0.5)$ as shown in Figure 19.

The coupled effect of reoxidation and collision agglomeration on inclusion removal is illustrated by comparing the two model curves in Figure 18. The better agreement of the lumped model for very small and very large sizes suggests that these two phenomena can account for the discrepancies observed in Figure 17. Collisions produce more large clusters, which lower the overall removal rate of inclusions larger than $50 \mu \mathrm{m}$. These same collisions reduce the number of small inclusions, which increases the overall removal rate of $5-50 \mu \mathrm{m}$ inclusions. Model removal rates for very small inclusions were dominated by the assumed generation rate. Note that collisions of the $0.5 \mu \mathrm{m}$ inclusions (assumed to be generated from reoxidation) were insufficient to evolve the size distribution enough to exactly match the low removal rates measured for inclusions up to $20 \mu \mathrm{m}$. Assuming that the collision rate predicted by the 
model in Appendix I is reasonable, this suggests that the actual generation of new inclusions occurs over a larger size range, possibly up to $10 \mu \mathrm{m}$.

The great effect that inclusion generation has on the entire evolved size distribution shows how important it is to minimize inclusion generation. Surface reoxidation must be avoided by careful control of the inert atmosphere above the tundish, or by the careful application and control of the tundish flux. Flux is best applied only over the second chamber of this tundish, where the flow is quiet enough to avoid its entrainment. If flux is applied, care must be taken to control its composition to ensure that it can remove inclusions that contact it. In addition, surface flow conditions must be controlled to ensure that inclusions are not created there, especially during transient events, such as ladle exchanges and level drops. The next section investigates one such transient event, assuming that such control has been achieved.

\section{TRANSIENT SIMULATIONS}

\section{A. Transient Fluid Flow and Temperature}

Just after a ladle exchange, the steel temperature leaving the new ladle is usually higher than that already in the tundish. Assuming an inlet temperature of $1853 \mathrm{~K}$, an initial uniform steel temperature in the tundish of $1843 \mathrm{~K}$, an initial steady-state flow field, and constant level, the transient temperature distribution and flow pattern were calculated using a time dependent model. Figures 20 and 21 show the velocity vectors and the temperature distribution at $100 \mathrm{sec}$ after the new ladle opens. The flow pattern is seen to be in transition. Figures 22 and 23 show corresponding results at $200 \mathrm{sec}$, where the flow pattern has almost reached its new steady state. The temperature and turbulence distributions at $200 \mathrm{sec}$ are still far from steady state, however.

\section{B. Inclusion removal in transient flow}

Figure 24 compares the percentage of clusters removed under non-isothermal steady state flow conditions (Figures 6-8) with that based on flow at $200 \mathrm{sec}$ after a new ladle starts (Figure 22). Both lines were 
constructed using the best inclusion trajectory model $\left(5,000 \mathrm{~kg} / \mathrm{m}^{3}\right.$ cluster density with random walk model). Slightly more clusters are removed at $200 \mathrm{sec}$ than at steady state. This is likely due to the increased turbulence levels during the flow transition at $200 \mathrm{sec}$. Nevertheless, the difference is small.

\section{Transient inclusion concentration.}

The scalar diffusion model was used to simulate a new ladle containing 30 ppm concentration of $\mathrm{Al}_{2} \mathrm{O}_{3}$ inclusions opening into a tundish containing uniform 15 ppm $\mathrm{Al}_{2} \mathrm{O}_{3}$. Figures 25 and 26 show the $\mathrm{Al}_{2} \mathrm{O}_{3}$ concentration distributions at $400 \mathrm{sec}$ and 1,000 sec after the new ladle opens, respectively. Figure 27 shows the evolution of $\mathrm{Al}_{2} \mathrm{O}_{3}$ concentration at the outlet and at the sampling points. $\mathrm{Al}_{2} \mathrm{O}_{3}$ concentration in the second chamber is still changing even at $1,000 \mathrm{sec}$ after the new ladle starts. Concentration at the outlet and sampling point are almost the same, which contrasts with the results in Figure 17. This is likely because inclusion flotation, collisions, and reoxidation were all ignored in the scalar diffusion model.

The quantitative inclusion removal rates predicted with this model are most representative of small inclusion behavior, where Stokes flotation is negligible. It is significant to note, however, that the concentration is heading towards a steady state value near to the inlet value of $30 \mathrm{ppm}$, which indicates negligible inclusion removal. This contrasts with the random walk flotation results, such as in Figure 14, which predict significant removal rates, even for small inclusions, as previously discussed. Thus, the results of this model are best interpreted in a qualitative manner.

The predicted outlet concentration is always less than at the inlet. This contrasts with the measurements, which show the concentration of small inclusions increases, even though collision agglomeration removes many inclusions from the small size range. This finding is consistent with the previous conclusion that significant reoxidation must be occurring in the tundish, producing new inclusions in the smallest size range. 
The results show that $\mathrm{Al}_{2} \mathrm{O}_{3}$ concentration is still evolving even at 1,000 sec after the new ladle starts, if the $\mathrm{Al}_{2} \mathrm{O}_{3}$ concentration in the new ladle is different from that in the previous ladle. Since the tundish has dead zones in the second chamber, mixing in the second chamber is very slow. Even after 1,400 sec $(1.3$ residence times), the concentration at both the sample point and outlet are changing.

The concentration at 2,400 s is predicted to have reached steady state, so the sample measurements based on tundish samples obtained in this work should be representative of steady state. Samples taken earlier than about one residence time $(1,060 \mathrm{~s})$ would still be greatly influenced by the cleanliness of the previous ladle.

\section{EFFECT OF TUNDISH GEOMETRY}

The effect of tundish geometry is examined briefly, focusing on the aspect ratio. Specifically, the length of the second chamber (at top) was reduced from 3.1 to $2.1 \mathrm{~m}$ and the steel depth in the tundish was increased from 1.05 to $1.25 \mathrm{~m}$. The capacity of 30 tonnes, flow rate of 1.7 tonne/min, and all other conditions and parameters remained about the same. The calculated flow pattern is shown in Figure 28, based on the coupled 3-D turbulent flow and temperature model. Like the longer, shallower tundish, buoyant fluid moving through the hole in the dam rises, circulating fluid across the top of the tundish in a clockwise direction before exiting.

Inclusion flotation is evaluated by calculating the trajectories of 300 clusters, assuming a density of 5,000

$\mathrm{kg} / \mathrm{m}^{3}$ and using the random walk model with constant inclusion cluster size. The results are compared in Figure 29 with those for the longer, shallower tundish. The difference is very small. This prediction indicates that inclusion removal should not be greatly affected by decreasing the length and increasing the depth of the tundish, so long as the total residence time and flow pattern remain about the same. 


\section{CONCLUSIONS}

This work has taken preliminary steps towards a comprehensive treatment of inclusion removal during molten steel processing. Specifically, transient turbulent fluid flow and temperature evolution in a tundish has been calculated with 3-D models using FLUENT. The corresponding trajectories, flotation, collision and removal of inclusions have been modeled and calibrated through comparison with measured size distributions. The following conclusions have been obtained.

1) Thermal buoyancy completely changes the flow pattern in the second chamber of the tundish investigated. Hot, buoyant steel exits through the bottom of the dam into the cold second chamber, and then lifts upward. This aids inclusion removal, especially for smaller sizes. An isothermal model produces a completely reversed flow pattern, with short circuiting flow along the bottom, and less inclusion removal.

2) The concentration of inclusions smaller than $5 \mu \mathrm{m}$ equivalent solid sphere radius (10 $\mu \mathrm{m}$ estimated cluster radius) increases over that in the ladle, due to reoxidation. However, the number of larger inclusions is significantly reduced.

3) Lack of a protective tundish slag cover is responsible for reoxidation, as is well-known. The findings of this work suggest that reoxidation generates mainly small size inclusions $(<10 \mu$ m cluster radius $)$.

4) Model predictions are most consistent with measurements when inclusion removal is based on trajectories calculated through the 3-D non-isothermal flow pattern, including flotation based on a cluster density of $5,000 \mathrm{~kg} / \mathrm{m}^{3}$, and random motion due to turbulence. It is also important to include the evolution of the inclusion size distribution due to reoxidation increasing the number of small inclusions and collision agglomeration in proportion to the turbulence dissipation level. 
5) Inclusion concentration measured at the sample point is predicted to be higher than that exiting the tundish. Thus, samples should be taken as deep as possible to measure the concentration entering the submerged entry nozzle to the mold. They should also be taken several residence times after the ladle is opened, in order to avoid contamination from the previous ladle.

6) Large particles naturally float to the top surface much faster than small ones. Including turbulent motion using the random walk method makes the removal rates closer by promoting the transport of small inclusions, promoting collisions, and interrupting the flotation of large inclusions.

7) Inclusion removal rate varies greatly with size. With a protective slag cover, (no reoxidation) and with no collisions, over $30 \%$ of inclusions smaller than $10 \mu \mathrm{m}$ are predicted to be removed. Almost $100 \%$ of the inclusion clusters larger than $80 \mu \mathrm{m}$ should be removed. With reoxidation and collisions, these removal rates drop to about $0 \%$ and $75 \%$ respectively.

8) The flow pattern was found to reach steady state shortly after a new ladle opens, (within 200 sec or 0.2 residence times) but the tundish temperature and inclusion distributions remain unsteady for a much longer time. Inclusion concentration is still evolving even at 1,400 sec (1.3 residence times) after the new ladle opens, if the $\mathrm{Al}_{2} \mathrm{O}_{3}$ concentration in the new ladle is different from that in the previous ladle.

9) For the conditions assumed (which include the absence of top-surface reoxidation), the removal of inclusions appears not to depend on the tundish aspect ratio, so long as the volume (and corresponding residence time) is the same, and the flow pattern in both tundishes is the same, with no short circuiting or dead zones.

To fully quantify inclusion removal from molten steel flowing through a tundish, the three inclusion models described and applied in this work should be linked together more directly into a single comprehensive model. Such a model should incorporate all of the phenomena that this work has 
demonstrated to be important, (including flow pattern, thermal buoyancy, turbulent motion, collisions, flotation, reoxidation) in addition to explicitly simulating inclusion removal by attachment to the tundish walls and other refractories. Many more size distribution measurements are needed for better model calibration and verification, including the individual submodels. Finally, more parametric studies can be performed to optimize inclusion removal during molten steel processing.

\section{APPENDIX I: INCLUSION SIZE EVOLUTION MODEL}

The inclusion size evolution model predicts the change over time of the inclusion size distribution in a uniform volume of steel, representing the average conditions in the tundish. This model was described and applied previously in a study of inclusion removal from an RH Degasser. ${ }^{[10]}$ This lumped model is based on the average turbulent dissipation level from the fluid flow model, and includes the generation of small inclusions by reoxidation, inclusion agglomeration from collisions, and inclusion removal by flotation to the top surface. Figure 30 shows the overall calculation steps. The rest of this section explains the size evolution procedure and collision rate calculation.

The model is based on the conservation of inclusion mass within each size range and time step. Inclusion radii were discretized into $0.05 \mu \mathrm{m}$ intervals starting from $0-0.05 \mu \mathrm{m}$ with average radius $\mathrm{r}_{\mathrm{k}}$ in the $\mathrm{k}$-th size range. The rate of change of the number of inclusions in each size range, $f\left(r_{k}\right)$, is calculated by:

$$
\begin{aligned}
& \frac{d f\left(r_{k}\right)}{d t}=\frac{1}{2} \sum_{i=1}^{i=k-1} f\left(r_{i}\right) f\left(r_{k-i}\right) W\left(r_{i}, r_{k-i}\right) \\
& -\sum_{i=1}^{i \max } f\left(r_{i}\right) f\left(r_{k}\right) W\left(r_{i}, r_{k}\right)-S+G
\end{aligned}
$$

under the condition,

$$
r_{k-i}^{3}=r_{k}^{3}-r_{i}^{3}
$$


The four terms on the right-hand side of Eq.[18] represent mass generation (from the agglomeration of smaller particles, $\mathrm{i}$ and k-i), disappearance (from agglomeration into larger particles due to collision with every possible size range, $\left.r_{k}\right)$, flotation removal, and generation (from reoxidation etc.). $W\left(r_{i}, r_{k-i}\right)$ is the rate of collision between inclusions of radii $r_{i}$ and $r_{k-i}$ and $f\left(r_{k}\right)$ is the number of inclusions per unit volume of the size range with radius $r_{k} \pm 0.25 \mu \mathrm{m}$. $S$ is the rate of inclusion removal by flotation. $S$ varies with inclusion size and is found from the results of other models which account for both flotation and transport through the flow field, such as the trajectory-based results in Figure 17. G is the rate of creation of new inclusions from reoxidation or other generation processes, such as estimated from thermodynamic considerations.

Inclusion collisions occur mainly in turbulent eddies and are proportional to the turbulence dissipation rate and the difference in Stokes flotation rate between two particles,

$$
\mathrm{W}=\mathrm{W}_{\mathrm{t}}+\mathrm{W}_{\mathrm{s}}
$$

where $\mathrm{W}_{\mathrm{t}}=$ collision rate of inclusions in turbulence eddies, $\mathrm{W}_{\mathrm{s}}=$ rate of Stokes collision.

The collision rate in turbulence eddies is calculated using the Saffman and Turner model, Higashitani's theory and Stokes collision theory. The collision rate between two inclusions within the size ranges, $r_{i}$ and $r_{j}$, is expressed by the Saffman and Turner model ${ }^{[17]}$.

$$
W_{t}\left(r_{i}, r_{j}\right)=1.3 a\left(r_{i}+r_{j}\right)^{3}\left(\frac{\varepsilon \rho}{\mu_{o}}\right)^{0.5}
$$

The empirical coefficient of collision, a, was introduced by K. Nakanishi and J. Szekely ${ }^{[18]}$. They estimated $\mathrm{a}=0.27-0.63$ by comparing the calculated oxygen contents and the measured ones. The following equations, suggested by K. Higashitani et al., ${ }^{[19]}$ were used to find a in this work. 


$$
\begin{aligned}
& \log a=C_{1} \log N_{v}+C_{2} \\
& N_{v}=\frac{12\left(r_{i}+r_{j}\right)^{3}}{A} \sqrt{\frac{\varepsilon \rho \mu_{o} \pi}{15}}
\end{aligned}
$$

Here, $\mathrm{C}_{1}$ and $\mathrm{C}_{2}$ are empirical constants, $\mathrm{A}$ is the Hamaker constant, and $\mathrm{N}_{\mathrm{v}}$ is a non-dimensional number (ratio between the viscous force and van der Waals force). In this model, the collision rate increases with increasing particle size, increasing turbulence dissipation, and decreasing fluid viscosity.

The difference in flotation velocity between large and small inclusions also promotes collision. The Stokes collision rate, $\mathrm{W}_{\mathrm{s}}$, is found from Eq.[24] $]^{[20]}$

$$
W_{s}=\frac{2 \pi\left(\rho-\rho_{c}\right) g}{9 \mu_{o}}\left(r_{i}+r_{j}\right)^{3}\left|r_{i}-r_{j}\right|
$$

When the turbulence dissipation rate is small, then Stokes collision controls the collision rate.

\section{ACKNOWLEDGMENTS}

The authors are grateful to Kawasaki Steel for support of this research, and to Dr. K. Sorimachi in particular for helpful suggestions. Thanks are also due to the National Science Foundation (Grant DMI98-00274) for support of BGT, and to the National Center for Supercomputing Applications at the University of Illinois for computing time and use of the FLUENT code.

\section{REFERENCES}

1. H.Tanaka, R. Nishihara, I. Kitagawa and R. Tsujino : ISIJ Int., vol.33, No.12, 1993, pp.1238

2. K. H. Tacke and J. C. Ludwig : Steel Research, vol. 58, No.6, 1987, pp.262.

3. H. B. Kaufmann, A. Niedermayr, H. Sattler and A. Preuer : Steel Research, vol. 64, No.4, 1993, pp.203.

4. K.Tozawa, Y.Kato and T.Nakanishi, CAMP-ISIJ, vol.10, 1997, pp.105.

5. A. K. Sinha and Y. Sahai : ISIJ Int., vol. 33, No.5, 1993, pp556. 
6. J.W. Hlinka: "Water model for the quantitative simulation of the heat and fluid flow in liquid-steel refractory systems", in Mathematical Process models in Iron-Steel Making, The Metals Society, London, 1975, pp. 157-164.

7. S. Chakraborty and Y.Sahai : Ironmaking and Steelmaking, vol.19, No.6, 1992, pp.479

8. S. Chakraborty and Y.Sahai : Ironmaking and Steelmaking, vol.19, No.6, 1992, pp.488

9. J. de J.Barreto S., M.A.Barron Meza and R.D.Morales, ISIJ Int., vol.36, No.5, 1996, pp.543.

10. Y.Miki, B.G.Thomas, A.Dennisov and Y.Shimada: Iron and Steelmaker, vol. 24, No. 8, 1997, pp.3139

11. Fluent user's guide Vol.1-4, Fluent Inc., Lebanon, NH, 1995.

12. K.Asano and T.Nakano, Tetsu-to-hagane, vol.57, 1971, pp.1943-1951.

13. H. C. de Groh III, P. D. Weidman, R. Zakhem, S. Ahuja and C. Beckermann : Metal. Trans.B, vol.24B, Oct. 1993, pp.749-753.

14. R. Zakhem, P. D. Weidman and H. C. de Groh 3 : Metal. Trans.A, vol.23A, Aug., 1992, pp.21692181.

15. H.Yasuhara, Simura and S.Nabeshima, CAMP-ISIJ, vol. 5, 1996, pp.785.

16. Joo, S., R. I. L. Guthrie, and C.J. Dobson, Steelmaking Conference Proceedings, vol. 72, 1989, p. 401.

17. P.G.Saffman and J.S.Turner, J.Fluid Mech., vol. 1, 1956, pp.16-30.

18. K.Nakanishi and J.Szekely, Trans.ISIJ, vol. 15, 1975, pp.522-530.

19. K.Higashitani, K.Yamauchi, Y.Matsuno and G.Hosokawa, J.Chem.Eng.Jpn, vol.116, 1983, pp.299304.

20. Lindborg and K.Torssel, Trans. Metal. Soc., AIME,vol.242, 1968, pp.94-102.

Table 1 Standard conditions.

\begin{tabular}{cc}
\hline Total steel mass & 30 tonne \\
Inlet velocity, $\mathrm{V}_{\text {in }}$ & $0.43 \mathrm{~m} / \mathrm{sec}$ \\
Flow rate & $1.7 \mathrm{tonne} / \mathrm{min}$ \\
Mean residence time & $1060 \mathrm{~s}$ \\
Inlet temperature, $\mathrm{T}_{0}$ & $1853 \mathrm{~K}(2876 \mathrm{~F})$ \\
$\mu_{\mathrm{o}}$ & $0.0057 \mathrm{~kg} / \mathrm{ms}$ \\
$\rho_{0}$ & $7000 \mathrm{~kg} / \mathrm{m}^{3}$ \\
$\alpha$ & $1.3 * 10^{-4}$ \\
\hline
\end{tabular}




\section{NOMENCLATURE}

a collision coefficient in Eqs. 21 and 22

A Hamaker constant $=0.45 \times 10^{-20} \mathrm{~J}$

$\mathrm{A}_{\mathrm{in}}, \mathrm{A}_{\mathrm{s}}$ areas of tundish inlet and sample planes

(perpendicular to flow direction) $\left(\mathrm{m}^{2}\right)$

$\mathrm{C}_{\mathrm{D}}$ drag coefficient

$\mathrm{C}_{\mathrm{p}} \quad$ specific heat (liquid steel) $\left(\mathrm{J} \mathrm{kg}^{-1} \mathrm{~K}^{-1}\right)$

$\mathrm{C}_{\mu} \quad$ empirical constant $=0.09$

$\mathrm{C}$ inclusion mass concentration

$\mathrm{C}_{1} \quad$ empirical constant $=-0.24$

$\mathrm{C}_{2} \quad$ empirical constant $=0.047$

$\mathrm{C}_{\text {in }}$ inclusion concentration at inlet

$\mathrm{C}_{\mathrm{s}} \quad$ inclusion concentration at sample plane

$\mathrm{D}_{\text {eff }}$ effective diffusivity (liquid) $\left(\mathrm{m}^{2} \mathrm{~s}^{-1}\right)$

$\mathrm{D}_{0} \quad$ molecular diffusivity (liquid) $\left(\mathrm{m}^{2} \mathrm{~s}^{-1}\right)$

$\mathrm{D}_{\mathrm{c}} \quad$ inclusion cluster diameter $(\mathrm{m})$

$\mathrm{d}$ diameter of each small particle in a cluster $(\mathrm{m})$

$\mathrm{f}\left(\mathrm{r}_{\mathrm{k}}\right) \quad$ number of inclusions per unit volume

in size range $r_{k}\left(\# m^{-3}\right)$

$\mathrm{F}_{\mathrm{D}} \quad \operatorname{drag}\left(\mathrm{s}^{-1}\right)$

$\mathrm{g}_{\mathrm{i}} \quad$ gravity acceleration (i-component) $\left(\mathrm{m} \mathrm{s}^{-2}\right)$

$\mathrm{G}$ rate of inclusion generation $\left(\# \mathrm{~m}^{-3} \mathrm{~s}^{-1}\right)$

h enthalpy $\left(\mathrm{J} \mathrm{kg}^{-1}\right)$

$\mathrm{K}$ turbulent kinetic energy $\left(\mathrm{m}^{2} \mathrm{~s}^{-2}\right)$

$\mathrm{k}_{\mathrm{O}} \quad$ laminar thermal conductivity $\left(\mathrm{W} \mathrm{m}^{-1} \mathrm{~K}^{-1}\right)$

$\mathrm{k}_{\mathrm{eff}}$ effective thermal conductivity ( $\mathrm{W} \mathrm{m}^{-1} \mathrm{~K}^{-1}$ )

$\mathrm{N}$ number of solid particles per inclusion cluster

$\mathrm{N}_{\text {in }}$ number of inclusions entering tundish

$\mathrm{N}_{\text {out }}$ number of inclusions exiting tundish

$\mathrm{P} \quad$ static pressure $\left(\mathrm{N} \mathrm{s}^{-2}\right)$

$\mathrm{Pr}_{\mathrm{t}} \quad$ turbulent Prandtl Number $=0.9$

Q fraction of inclusions removed

Re Reynolds number $=\left|\mathrm{u}_{\mathrm{i}}-\bar{u}_{c i}\right| \mathrm{D}_{\mathrm{c}} \rho \mu_{\mathrm{o}}{ }^{-1}$

$\mathrm{R}_{\mathrm{c}}, \mathrm{r}_{\mathrm{i}}$ inclusion cluster circumambient radius (m)

$R_{m} \quad$ measured radius of equivalent-mass solid sphere $(\mathrm{m})$

$\mathrm{S} \quad$ rate of inclusion flotation removal $\left(\# \mathrm{~m}^{-3} \mathrm{~s}^{-1}\right)$

$\mathrm{Sc}_{\mathrm{t}} \quad$ turbulent Schmidt number $=1$

$\mathrm{t}$ time (s)

$\mathrm{T} \quad$ liquid steel temperature $\left({ }^{\circ} \mathrm{C}\right)$

$\mathrm{T}_{\mathrm{O}} \quad$ initial temperature (tundish inlet) $\left({ }^{\circ} \mathrm{C}\right)$

$\mathrm{u}_{\mathrm{i}} \quad$ mean liquid steel velocity component in $\mathrm{i}$ direction $\left(\mathrm{m} \mathrm{s}^{-1}\right)$

$\mathrm{u}^{\prime}{ }_{\mathrm{i}} \quad$ random fluctuation of velocity component $\mathrm{u}_{\mathrm{i}}\left(\mathrm{m} \mathrm{s}^{-1}\right)$ 


$\begin{array}{ll}\mathrm{u}_{\mathrm{ci}} & \text { inclusion velocity component in i direction }\left(\mathrm{m} \mathrm{s}^{-1}\right) \\ \bar{u}_{c i} & \text { mean inclusion velocity component }\left(\mathrm{m} \mathrm{s}^{-1}\right) \\ \mathrm{V}_{\mathrm{in}} & \text { liquid velocity at tundish inlet }\left(\mathrm{m} \mathrm{s}^{-1}\right) \\ \mathrm{V}_{\mathrm{s}} & \text { calculated liquid velocity at sample plane }\left(\mathrm{m} \mathrm{s}^{-1}\right) \\ \mathrm{W} & \text { collision rate }\left(\mathrm{m}^{3} \mathrm{~s}^{-1}\right) \\ \mathrm{x}_{\mathrm{i}}, \mathrm{x}_{\mathrm{j}} & \text { coordinate direction }(\mathrm{x}, \mathrm{y}, \text { or } \mathrm{z})\left(\mathrm{m} \mathrm{s}^{-1}\right) \\ \alpha & \text { volumetric thermal expansion coefficient }\left(\mathrm{m}^{3} \mathrm{~m}^{-3}\right) \\ \beta & \text { volume fraction of } \mathrm{Al}_{2} \mathrm{O}_{3} \text { in a cluster } \\ \varepsilon & \text { turbulence dissipation rate }\left(\mathrm{m}^{2} \mathrm{~s}^{-3}\right) \\ \mu_{\mathrm{eff}} & \text { liquid effective viscosity }\left(\mathrm{kg} \mathrm{m}^{-1} \mathrm{~s}^{-1}\right) \\ \mu_{\mathrm{O}} & \text { liquid laminar }(\text { molecular}) \mathrm{viscosity}\left(\mathrm{kg} \mathrm{m}^{-1} \mathrm{~s}^{-1}\right) \\ \mu_{\mathrm{t}} & \text { liquid turbulent viscosity }\left(\mathrm{kg} \mathrm{m}^{-1} \mathrm{~s}^{-1}\right) \\ \rho & \text { liquid steel density }\left(\mathrm{kg} \mathrm{m}^{-3}\right) \\ \rho_{\mathrm{O}} & \text { initial liquid density at inlet }\left(\mathrm{kg} \mathrm{m}^{-3}\right) \\ \rho_{\mathrm{c}} & \text { inclusion cluster density }\left(\mathrm{kg} \mathrm{m}^{-3}\right) \\ \rho_{\mathrm{Al}_{2} \mathrm{O}_{3}} & \text { density of } \mathrm{Al}_{2} \mathrm{O}_{3}\left(\mathrm{~kg} \mathrm{~m} \mathrm{~m}^{-3}\right)\end{array}$




\section{LIST OF FIGURES}

Figure 1 Tundish geometry.

Figure 2 Inclusion cluster schematics showing radius and density for equivalent flotation models.

* Sphere with the same mass as measured inclusion from laser diffraction scattering

Figure 3 Measured inclusion size distribution in ladle and tundish. (bin size $=1.0 \mu \mathrm{m}$ in radius)

a) Number concentration

b) Mass concentration

Figure 4 Calculated steady molten steel flow distribution at center plane (isothermal model)

Figure 5 Calculated steady flow distribution at quarter plane (isothermal model)

Figure 6 Calculated steady molten steel flow distribution at center plane (coupled flow-temperature model)

Figure 7 Calculated steady flow distribution at quarter plane (coupled flow-temperature model)

Figure 8 Calculated steady flow distribution near wall (coupled flow-temperature model)

Figure 9 Steady temperature distribution at center plane.

(1833-1853 K temperature range.)

Figure 10 Steady kinetic energy distribution at center plane $\left(\mathrm{m}^{2} / \mathrm{s}^{2}\right)$

(coupled flow-temperature model)

Figure 11 Steady turbulence dissipation rate distribution at center plane $\left(\mathrm{m}^{2} / \mathrm{s}^{3}\right)$

(coupled flow-temperature model)

Figure 12 Typical inclusion trajectory (in steady, non-isothermal flow field)

Figure 13 Typical inclusion trajectory using random walk model (in steady, non-isothermal flow field)

Figure 14 Comparison of fraction of inclusion clusters removed in tundish for isothermal and nonisothermal models.

Figure 15 Comparison of fraction of inclusion clusters removed for different non-isothermal models

Figure 16 Fraction of inclusions removed in each tundish chamber. $\left(5,000 \mathrm{~kg} / \mathrm{m}^{3}\right.$ cluster density with random walk model.) 
Figure 17 Comparison of cluster size distribution at sample position and in ladle. $\left(5,000 \mathrm{~kg} / \mathrm{m}^{3}\right.$ cluster density with random walk model, no collision, and no generation.)

Figure 18 Fraction of inclusion clusters removed in tundish.

Figure 19 Schematic of equivalent clusters for flotation model.

Figure 20 Calculated flow distribution at $100 \mathrm{sec}$ after new ladle starts (non-isothermal transient model) Figure 21 Calculated temperature distribution at $100 \mathrm{sec}$ after new ladle starts.

(1828 - $1853 \mathrm{~K}$ temperature range)

Figure 22 Steel velocity vector at $200 \mathrm{sec}$ after new ladle starts.

Figure 23 Temperature distribution at $200 \mathrm{sec}$ after new ladle starts.

(1833-1853 K temperature range.)

Figure 24 Comparison of clusters removed at steady state and at $200 \mathrm{sec}$ after new ladle opens.

Figure $25 \mathrm{Al}_{2} \mathrm{O}_{3}$ concentration at $400 \mathrm{sec}$

Figure $26 \mathrm{Al}_{2} \mathrm{O}_{3}$ concentration at $1,000 \mathrm{sec}$

Figure 27 Evolution of $\mathrm{Al}_{2} \mathrm{O}_{3}$ concentration at sample position and at tundish outlet (scalar diffusion model)

Figure 28 Calculated molten steel flow distribution at center plane (non-isothermal model with new geometry)

Figure 29 Comparison of fraction of removed clusters between standard and new tundish geometry (trajectory model based on Figure 6-8 flow).

Figure 30 Inclusion size evolution model flow chart 


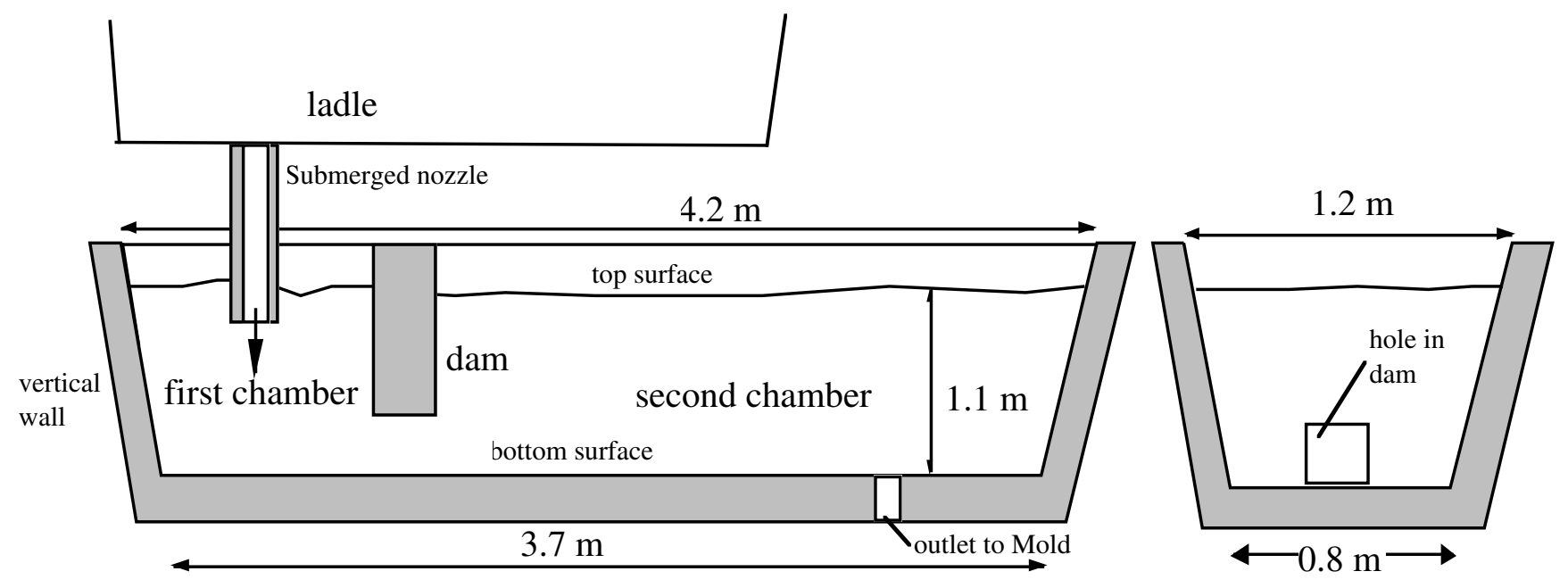

Figure 1 Tundish geometry.

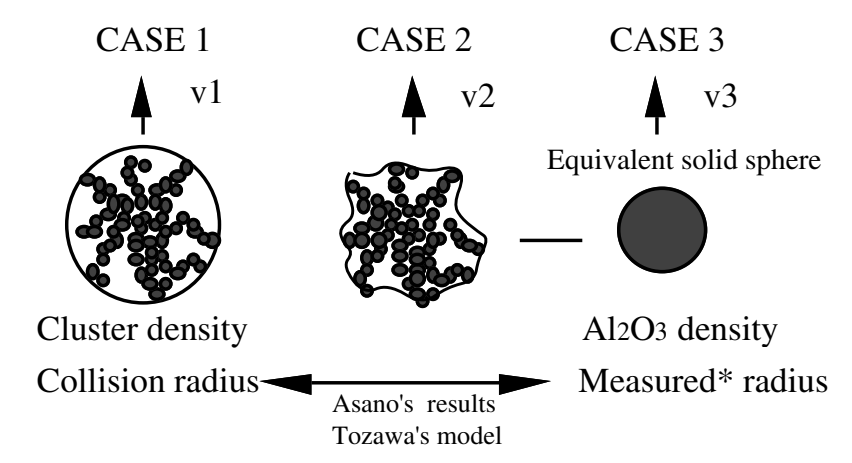

Figure 2 Inclusion cluster schematics showing radius and density for equivalent flotation models.

* Sphere with the same mass as measured inclusion from laser diffraction scattering) 


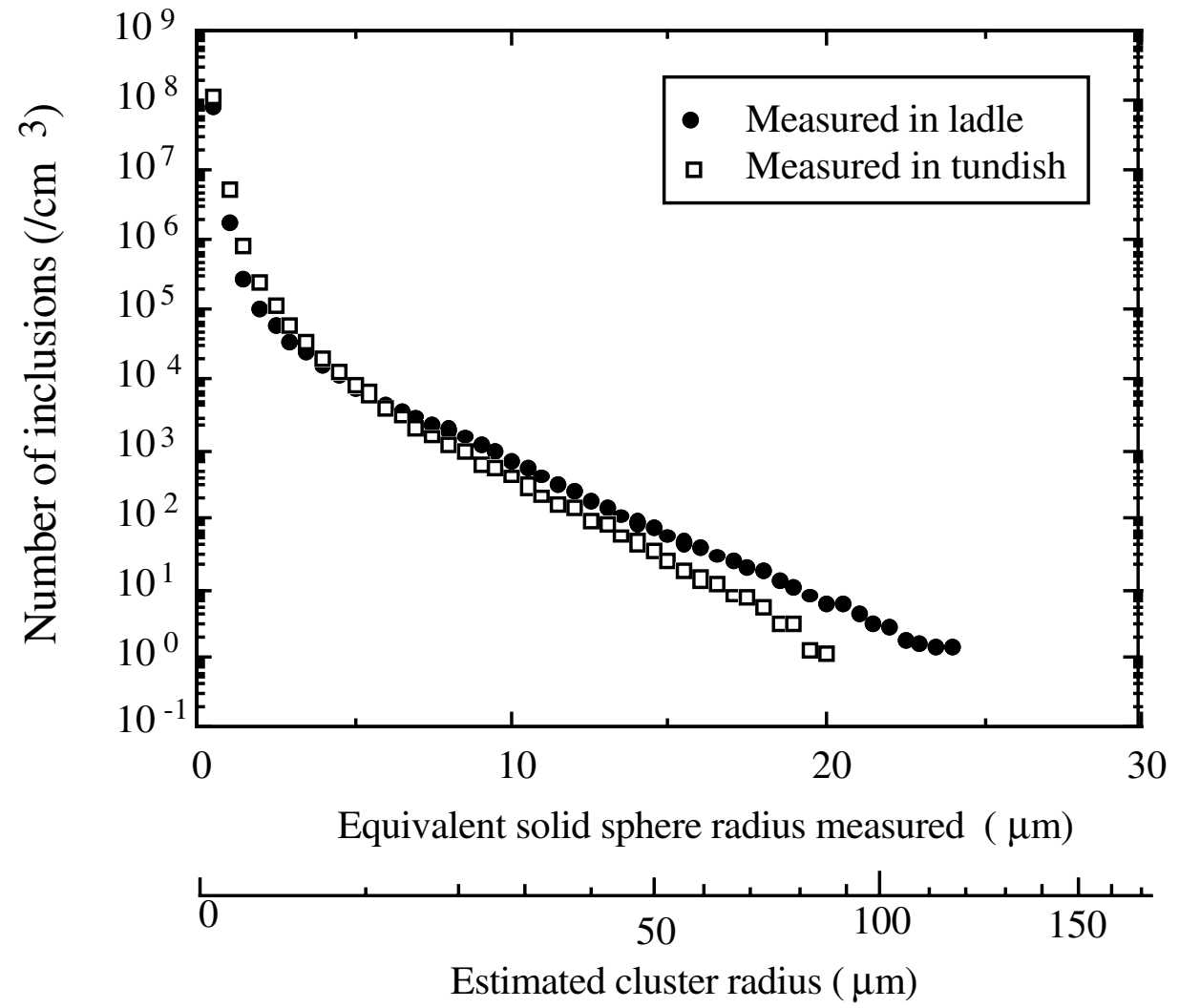

a)

Figure 3) 


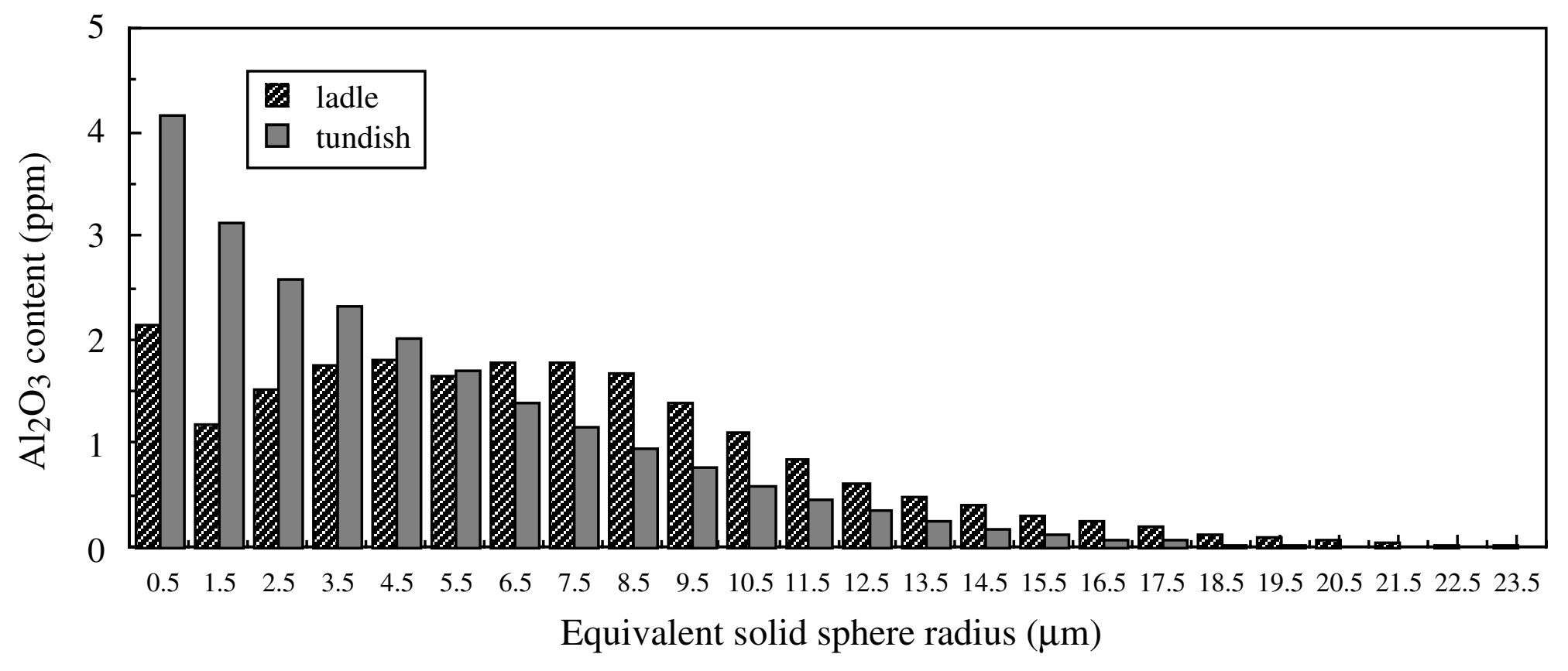

b)

Fig.3 Measured inclusion size distribution in ladle and tundish. (bin size $=1.0 \mu \mathrm{m}$ in radius)

a) Number concentration

b) Mass concentration 


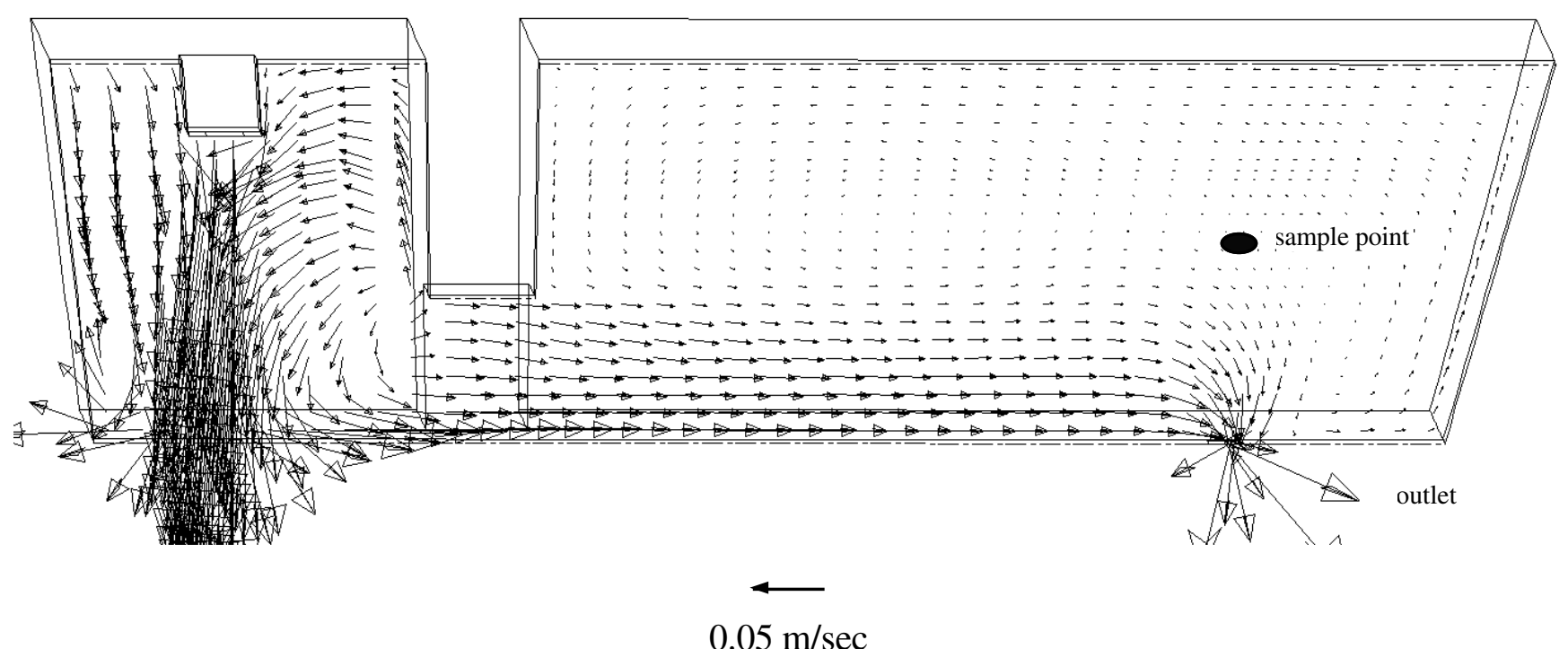

Figure 4 Calculated steady molten steel flow distribution at center plane (isothermal model)

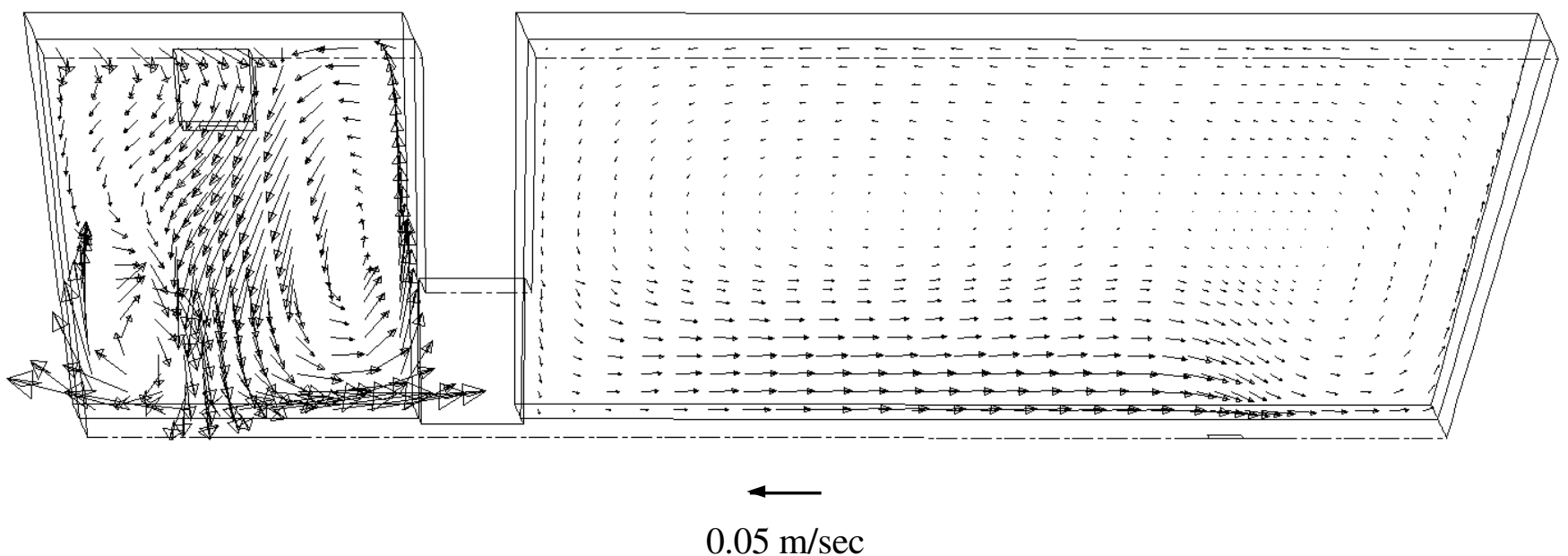

Figure 5 Calculated steady flow distribution at quarter plane (isothermal model) 


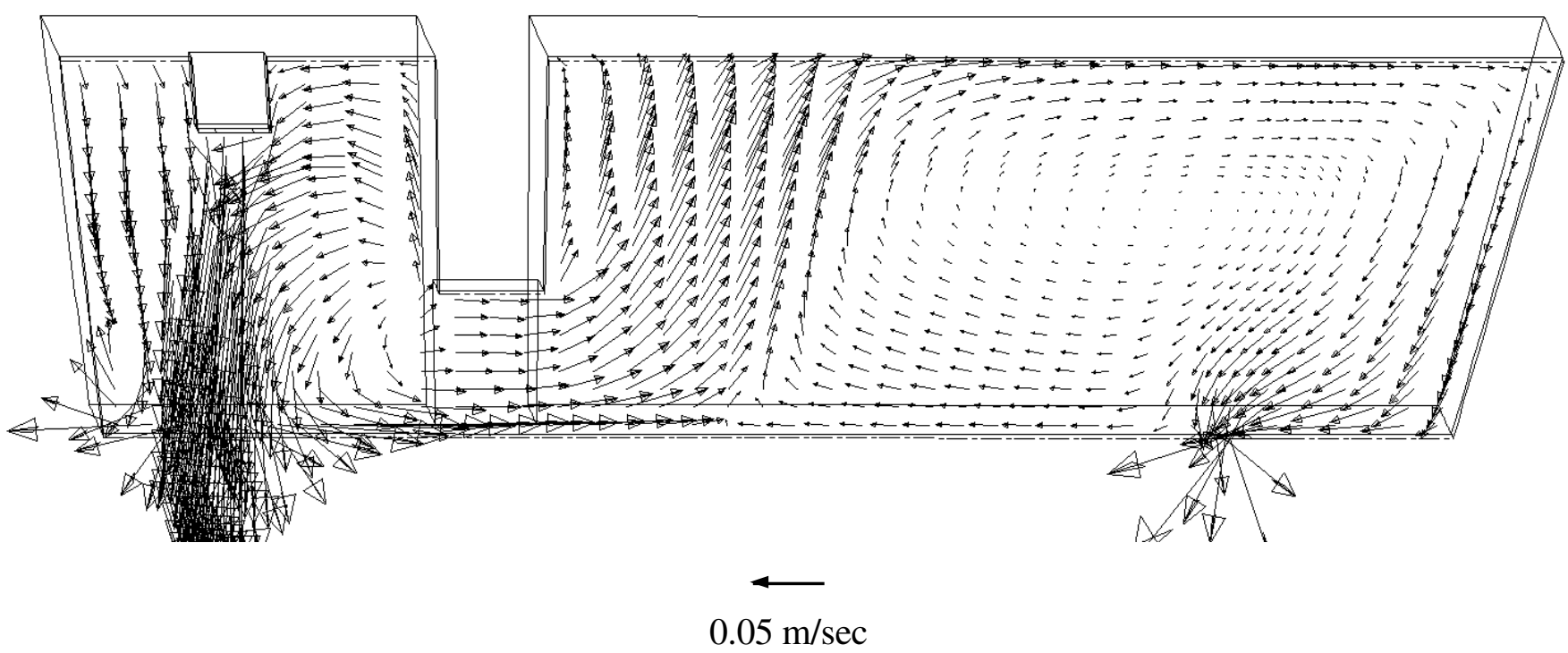

Figure 6 Calculated steady molten steel flow distribution at center plane (coupled flow-temperature model)

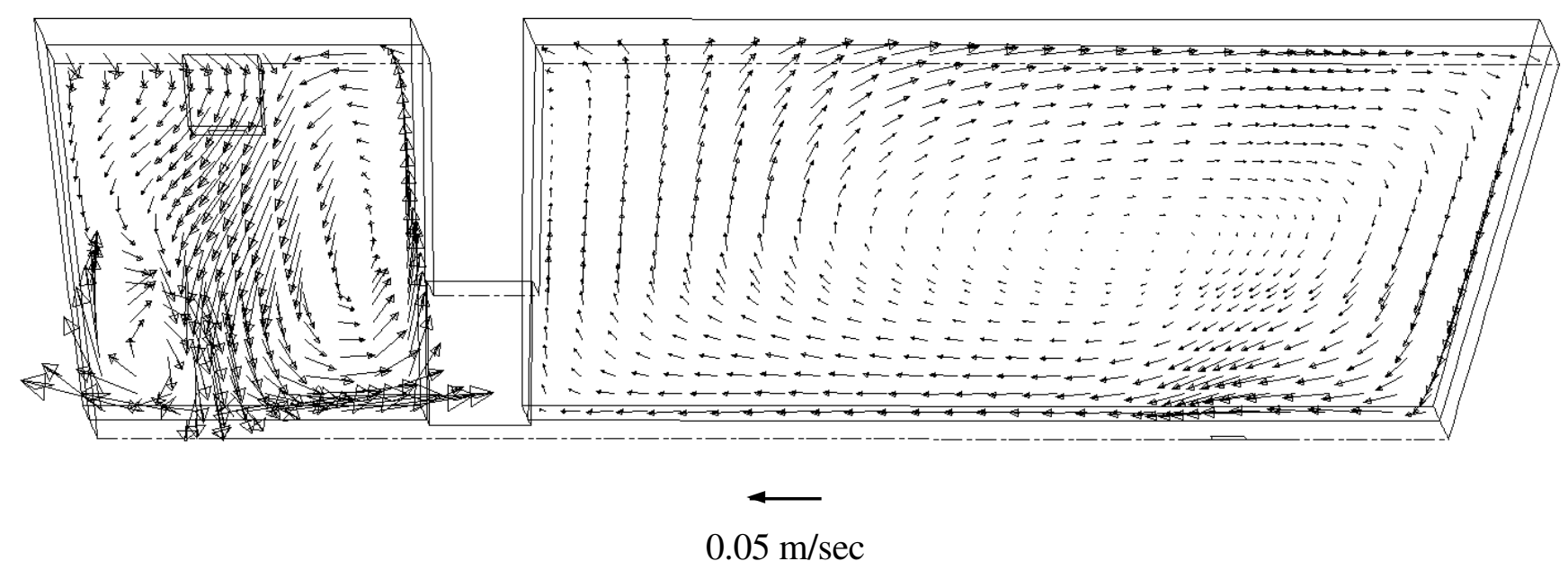

Figure 7 Calculated steady flow distribution at quarter plane (coupled flow-temperature model) 

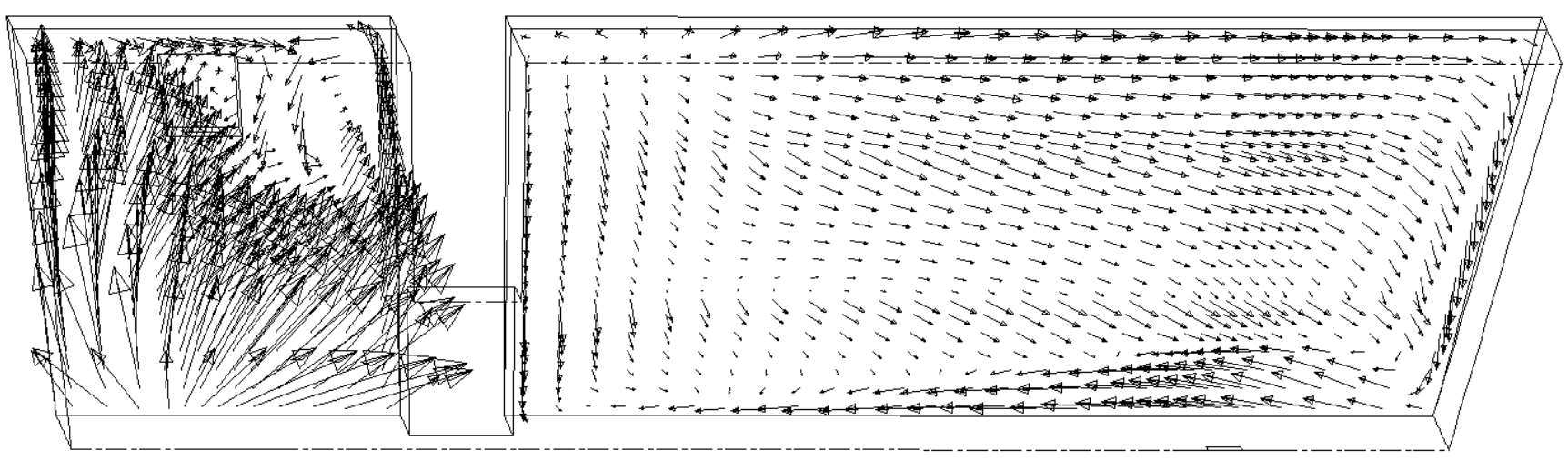

$0.05 \mathrm{~m} / \mathrm{sec}$

Figure 8 Calculated steady flow distribution near wall (coupled flow-temperature model)

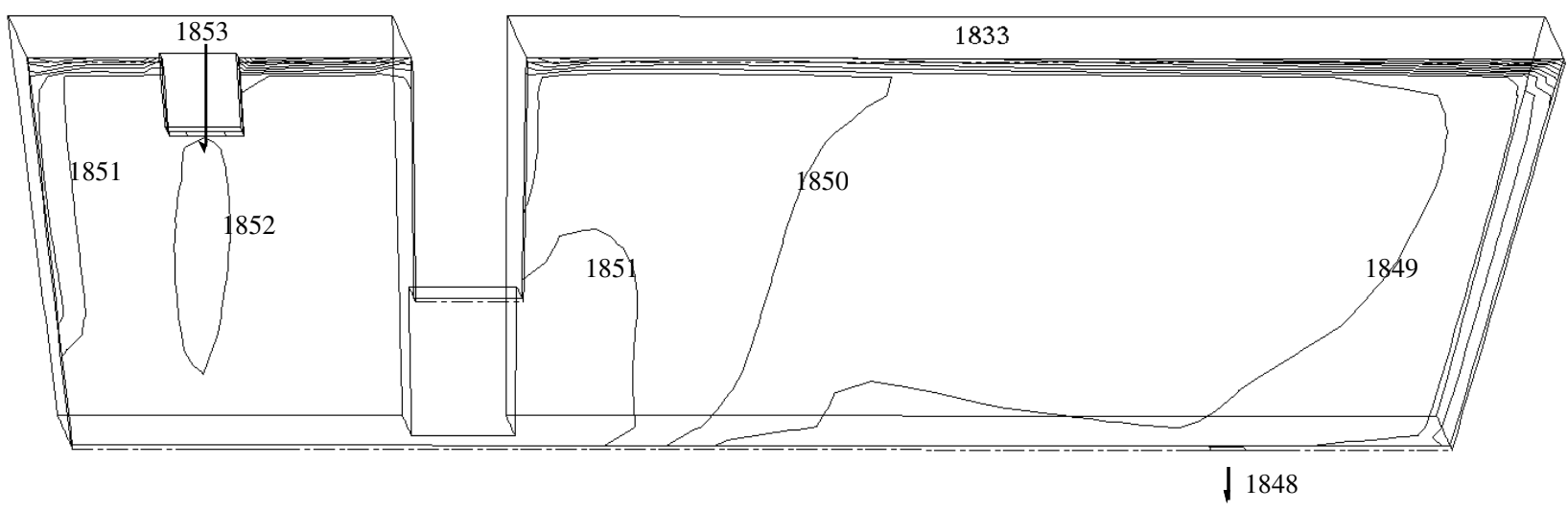

Figure 9 Steady temperature distribution at center plane.

(1833-1853 K temperature range.) 


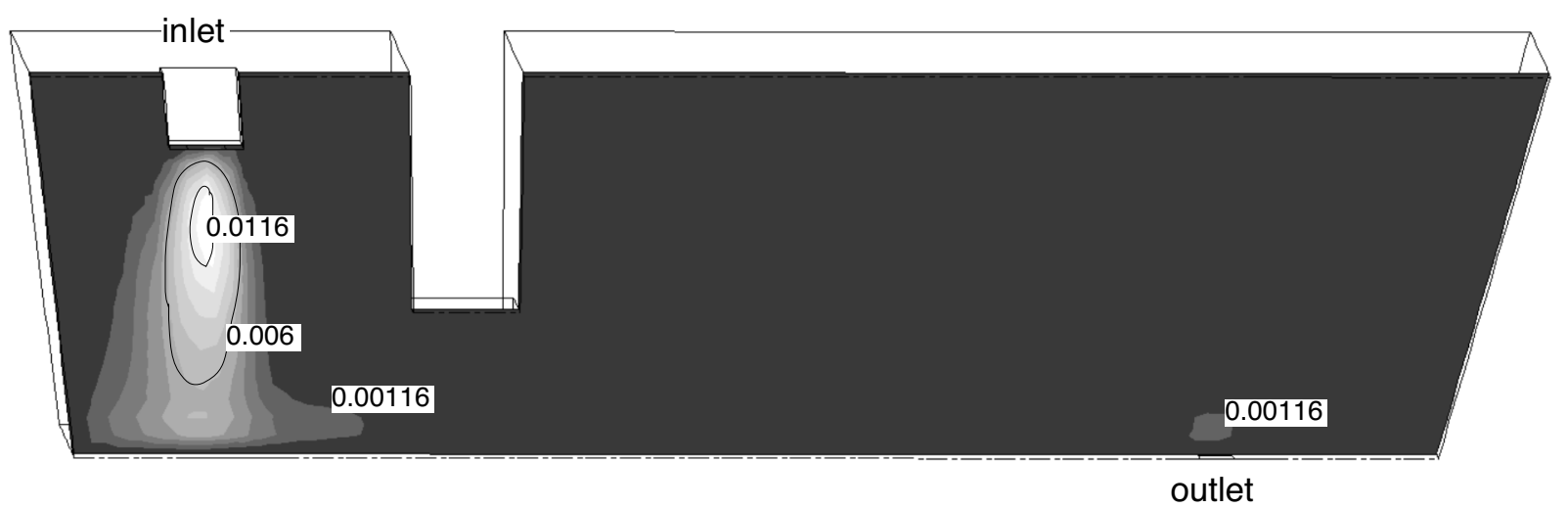

Figure 10 Distribution of kinetic energy on center plane $\left(\mathrm{m}^{2} / \mathrm{s}^{2}\right)$ (coupled flow-temperature model)

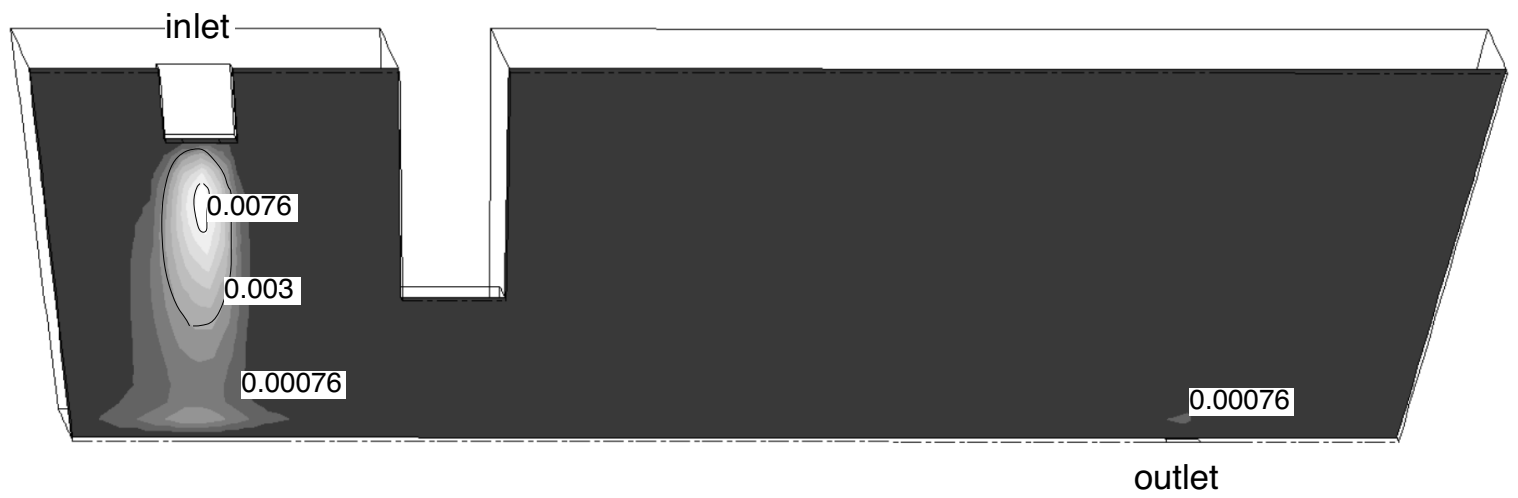

Figure 11 Steady turbulence dissipation rate distribution at center plane $\left(\mathrm{m}^{2} / \mathrm{s}^{3}\right)$ (coupled flow-temperature model) 


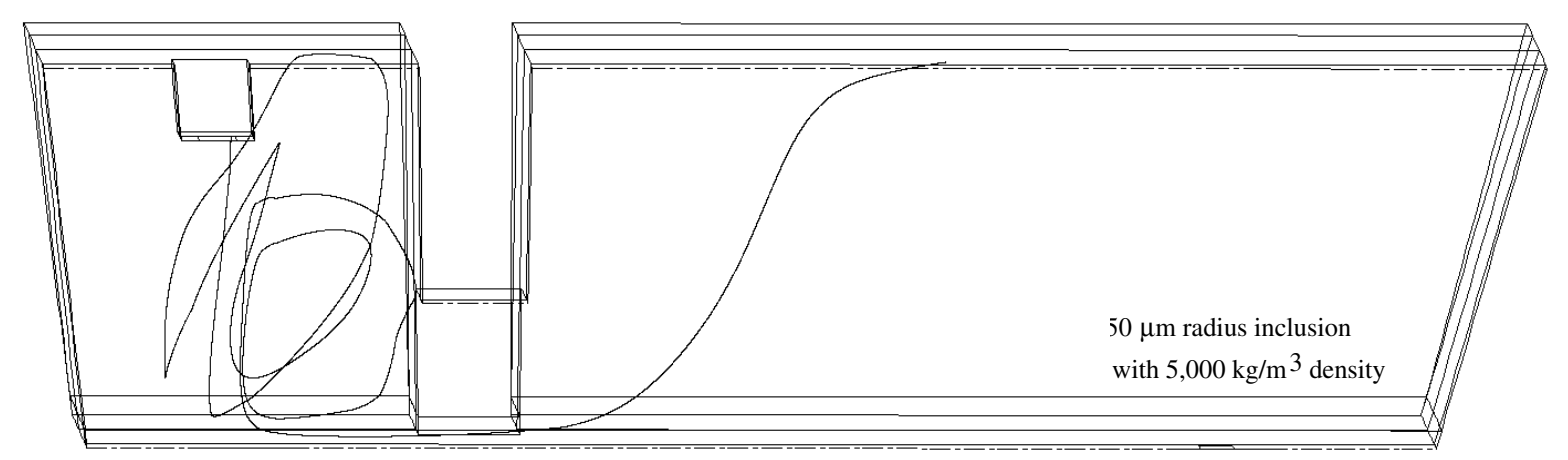

Figure 12 Typical inclusion trajectory (in steady, non-isothermal flow field)

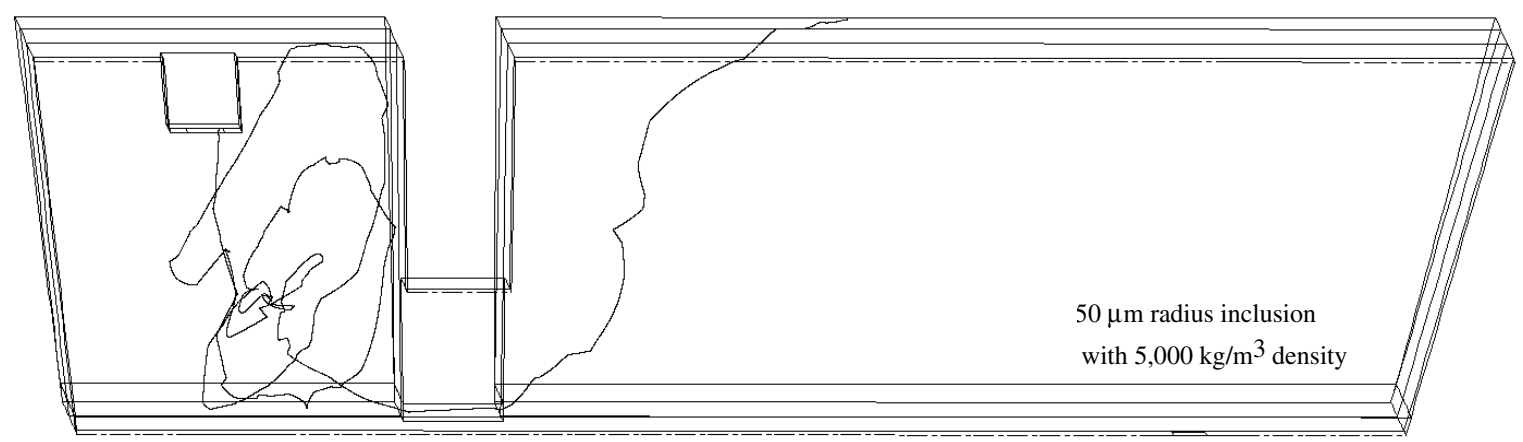

Figure 13 Typical inclusion trajectory using random walk model (in steady, non-isothermal flow field) 


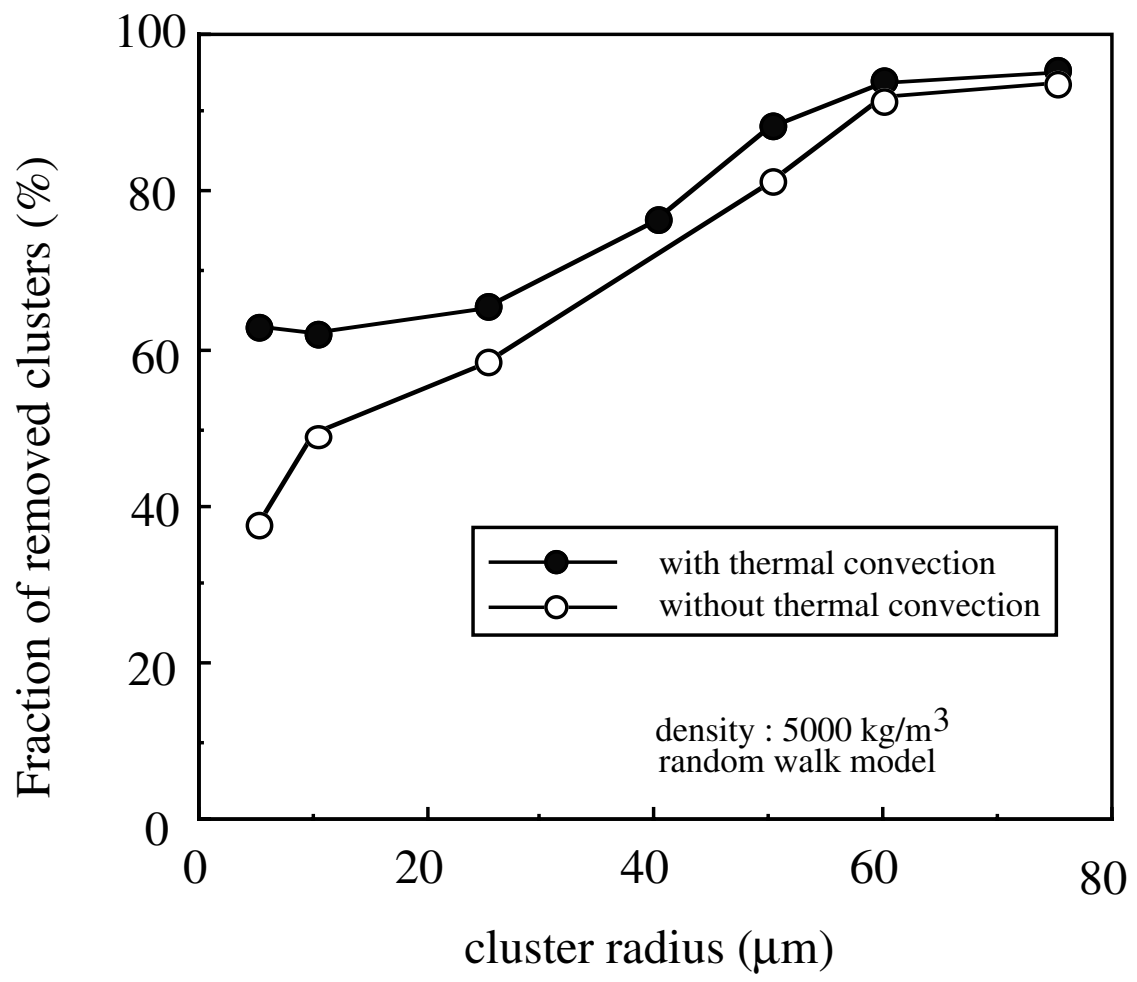

Figure 14 Comparison of fraction of inclusion clusters removed in tundish for isothermal and non-isothermal models. 


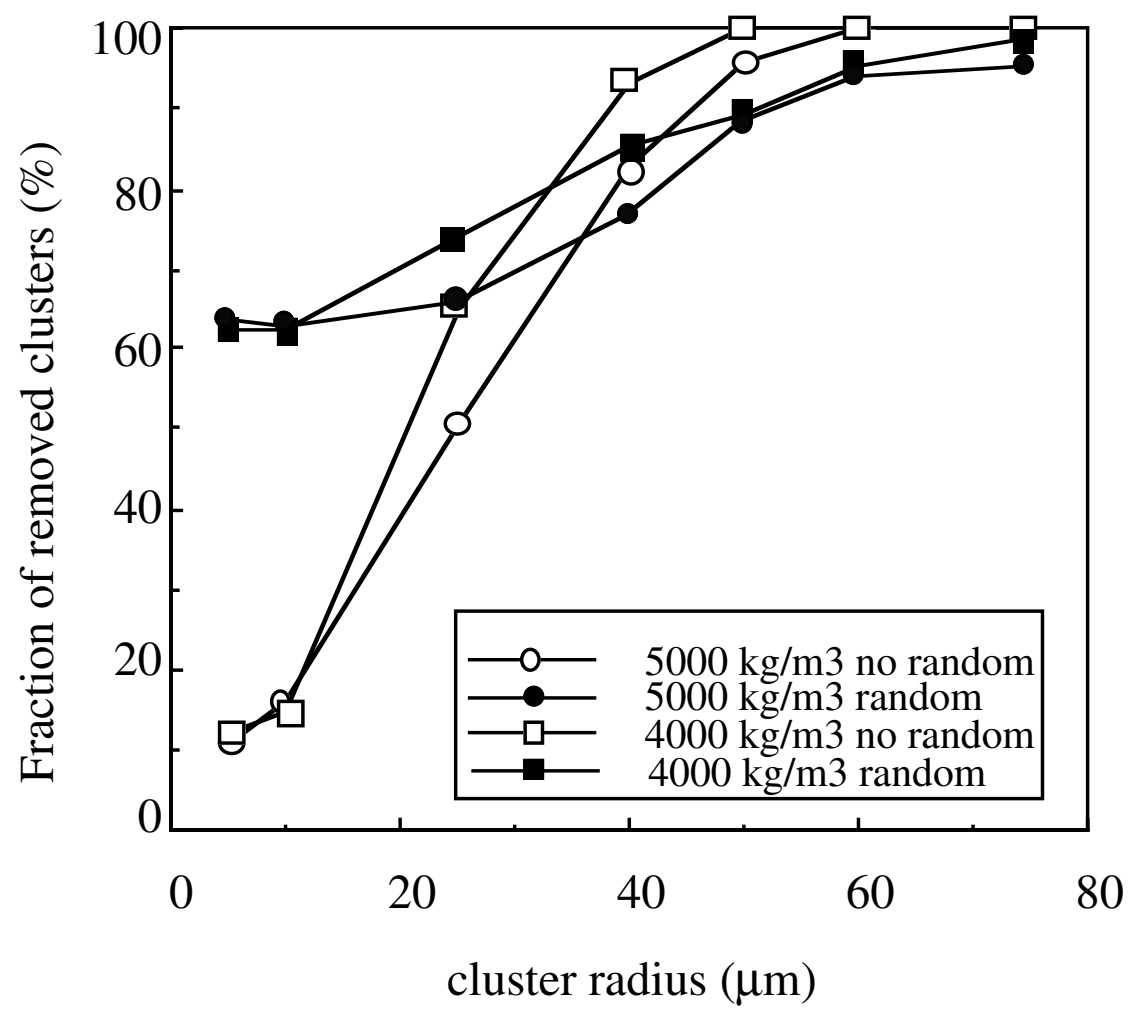

Figure 15 Comparison of fraction of inclusion clusters removed for different non-isothermal models 


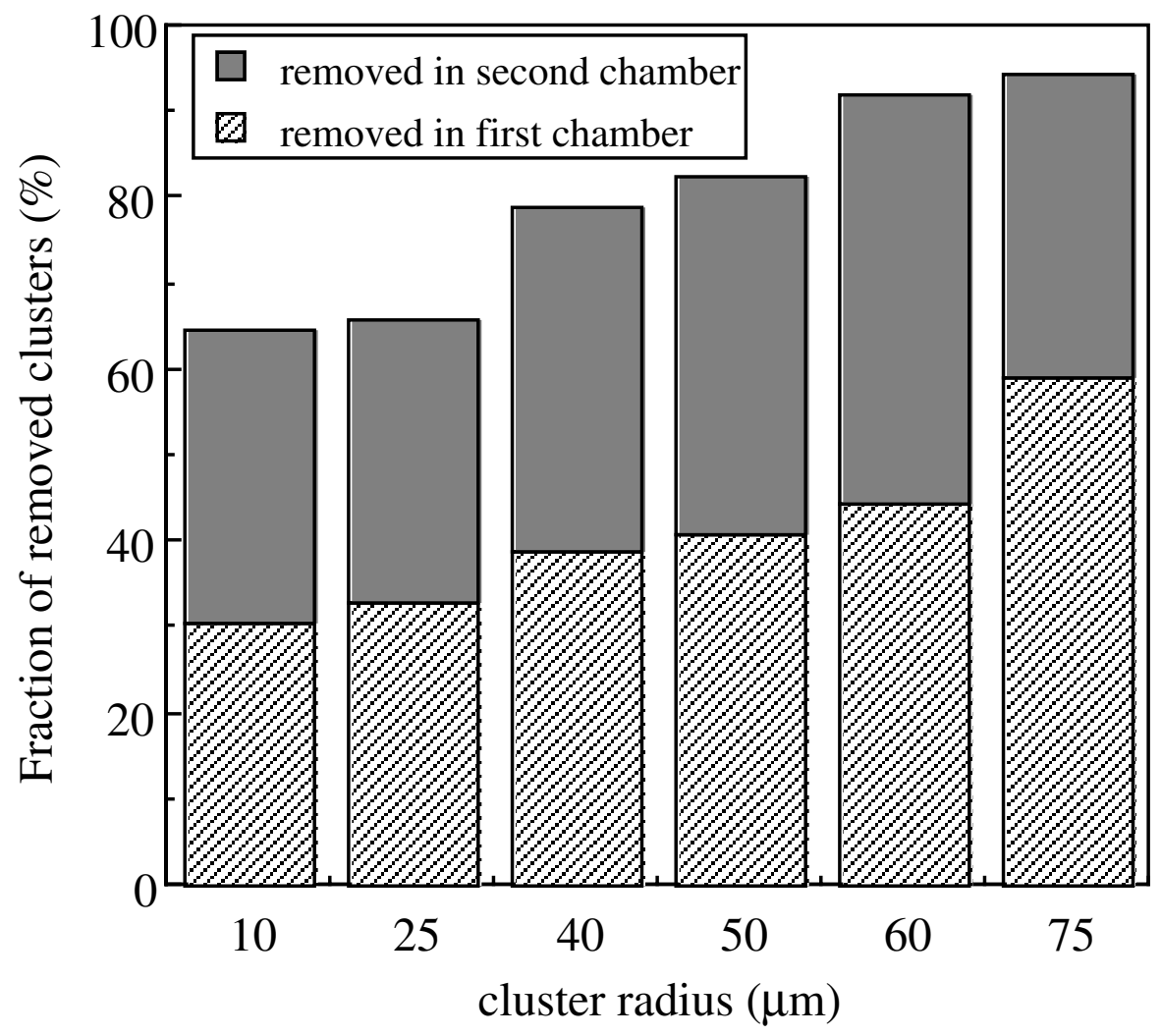

Figure 16 Fraction of inclusions removed in each tundish chamber.

$\left(5,000 \mathrm{~kg} / \mathrm{m}^{3}\right.$ cluster density with random walk model. $)$ 


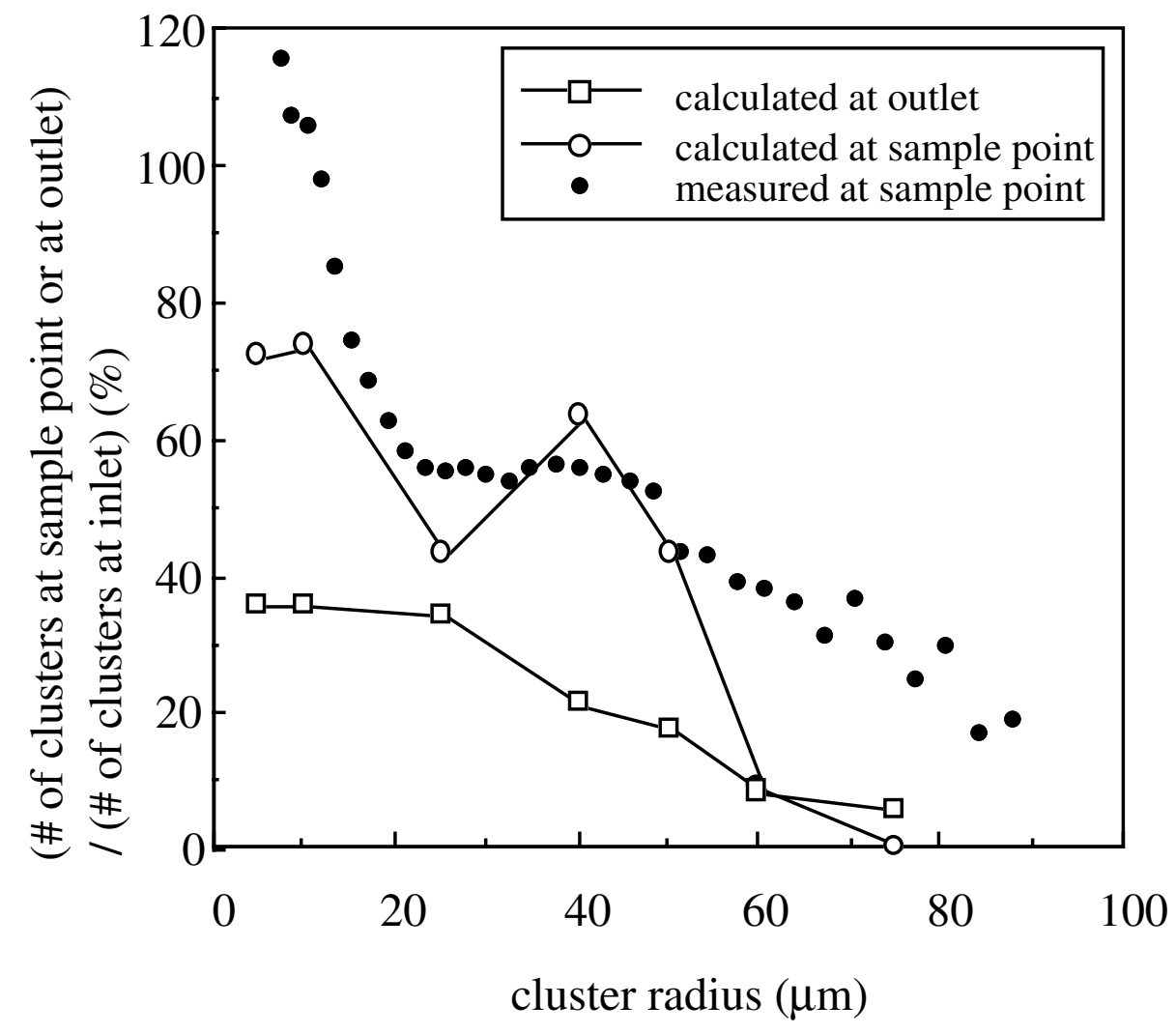

Figure 17 Comparison of cluster size distribution at sample position and in ladle.

$\left(5,000 \mathrm{~kg} / \mathrm{m}^{3}\right.$ cluster density with random walk model, no collision, and no generation.) 


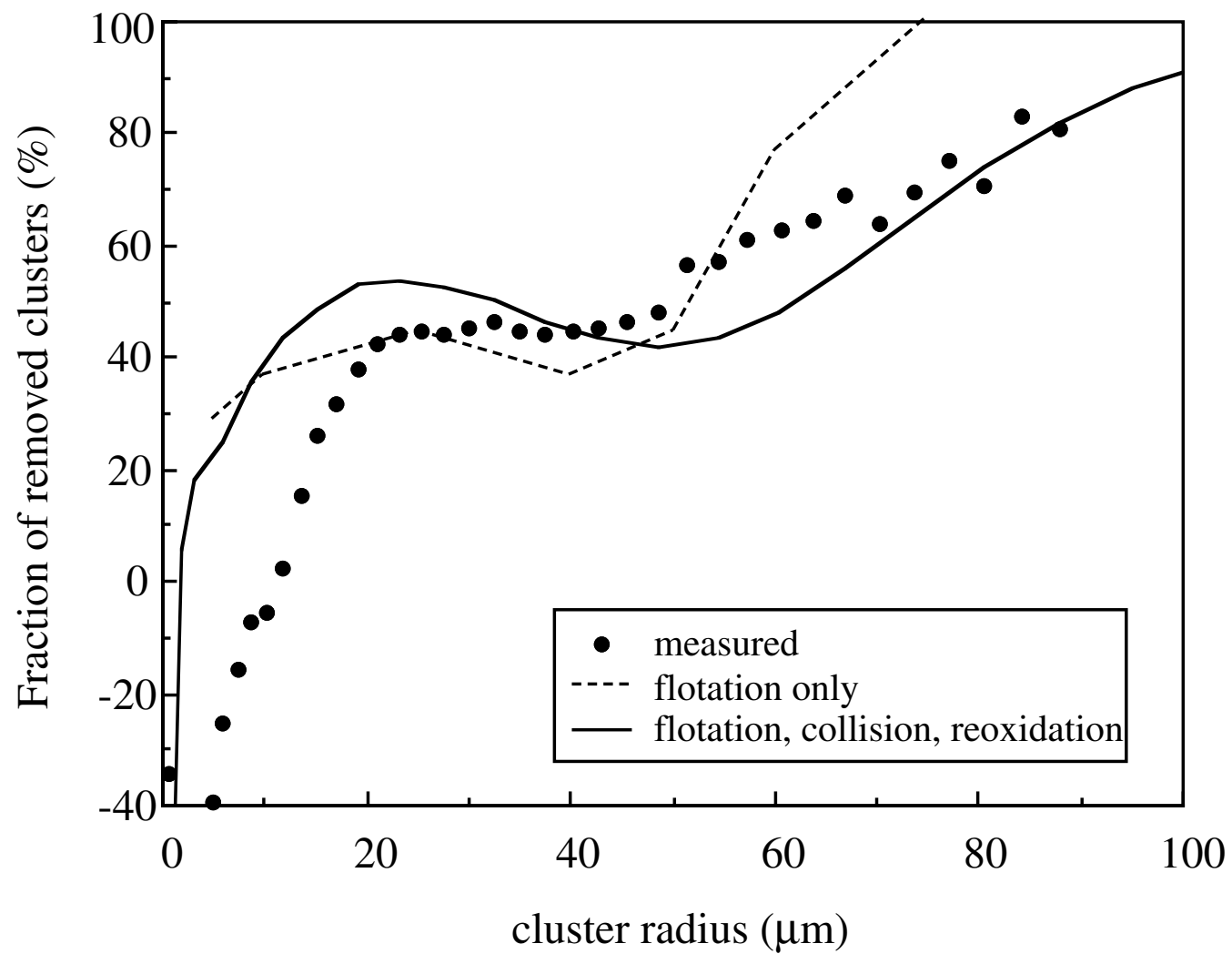

Figure 18 Fraction of inclusion clusters removed in tundish. 


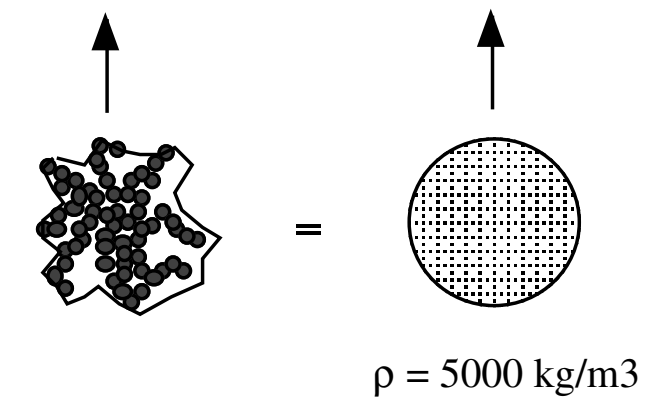

Figure 19 Schematic of equivalent clusters for flotation model.

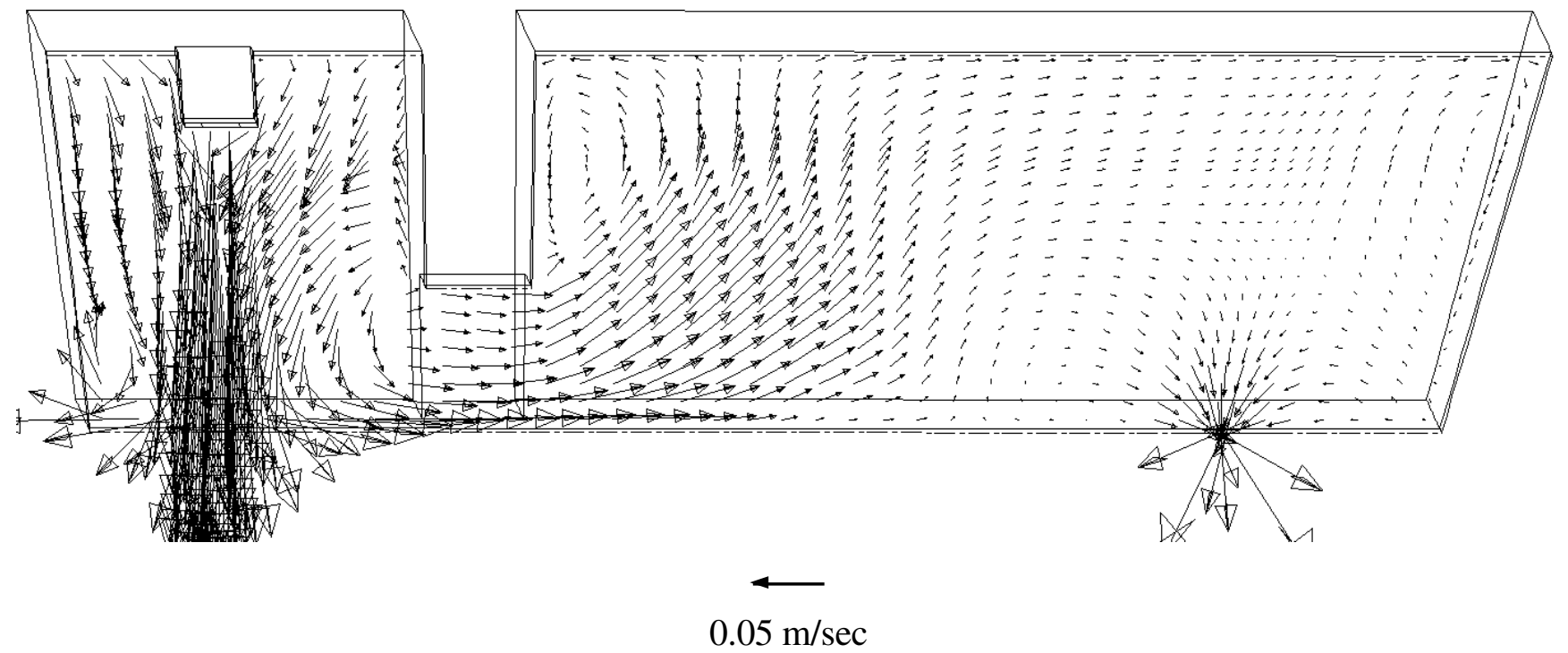

Figure 20 Calculated flow distribution at $100 \mathrm{sec}$ after new ladle starts (non-isothermal transient model) 


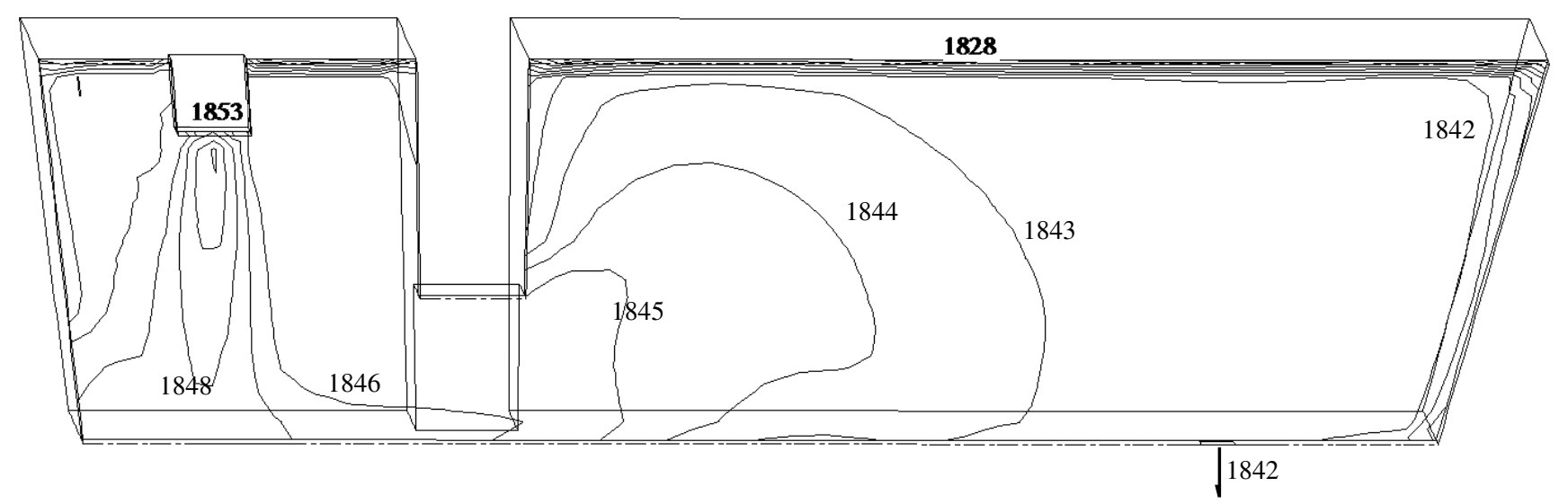

Figure 21 Calculated temperature distribution at $100 \mathrm{sec}$ after new ladle starts. (1828 - $1853 \mathrm{~K}$ temperature range)

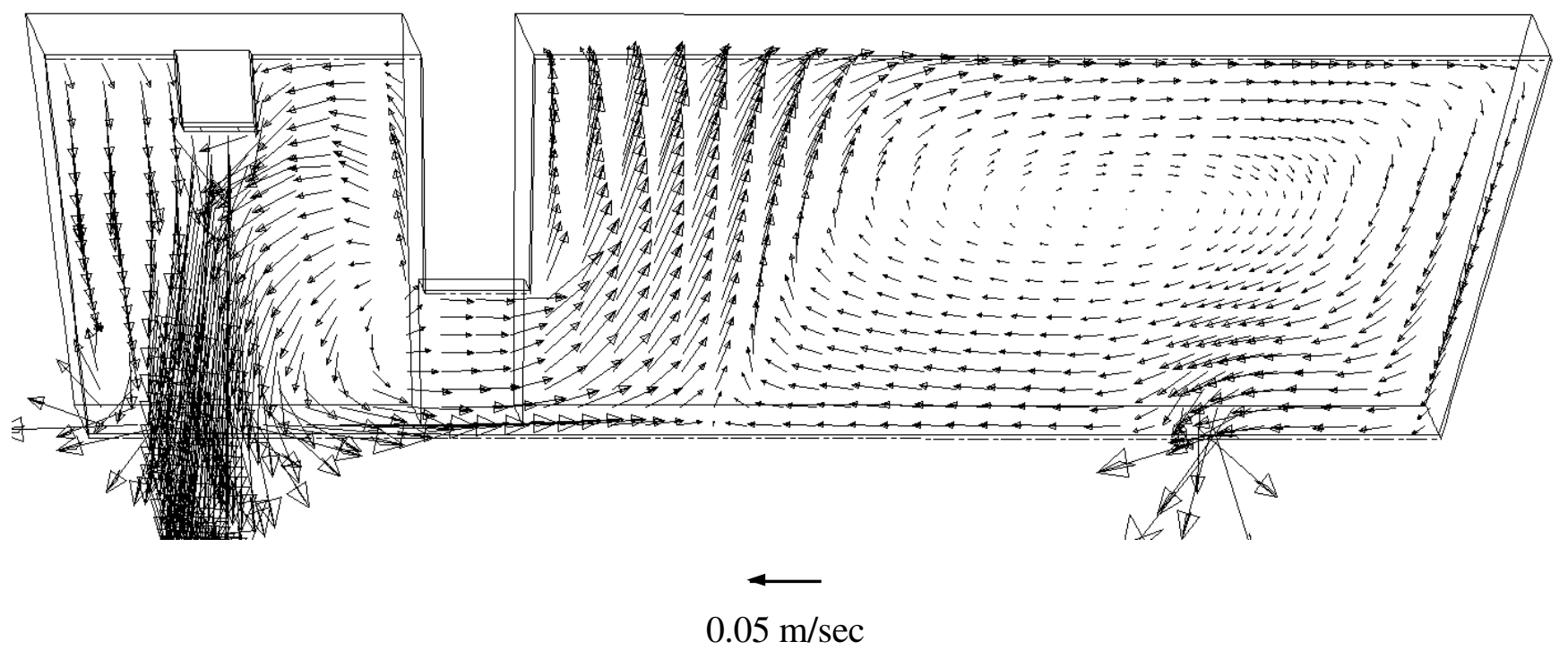

Figure 22 Steel velocity vector at $200 \mathrm{sec}$ after new ladle starts. 


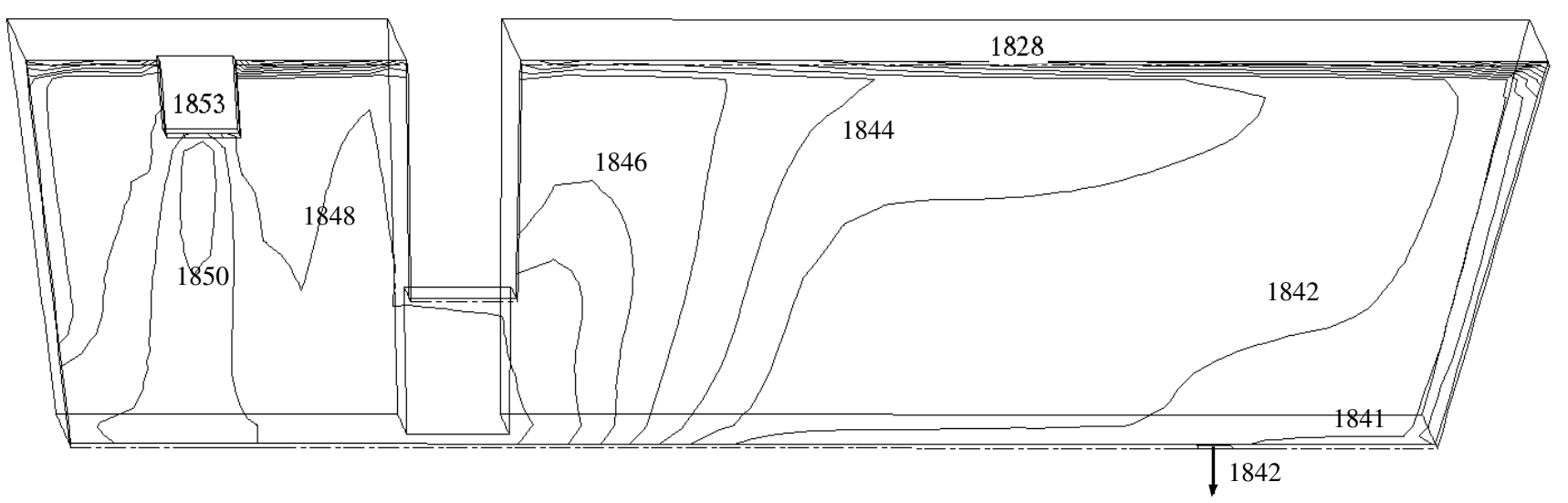

Figure 23 Temperature distribution at $200 \mathrm{sec}$ after new ladle starts. (1833-1853 K temperature range.) 


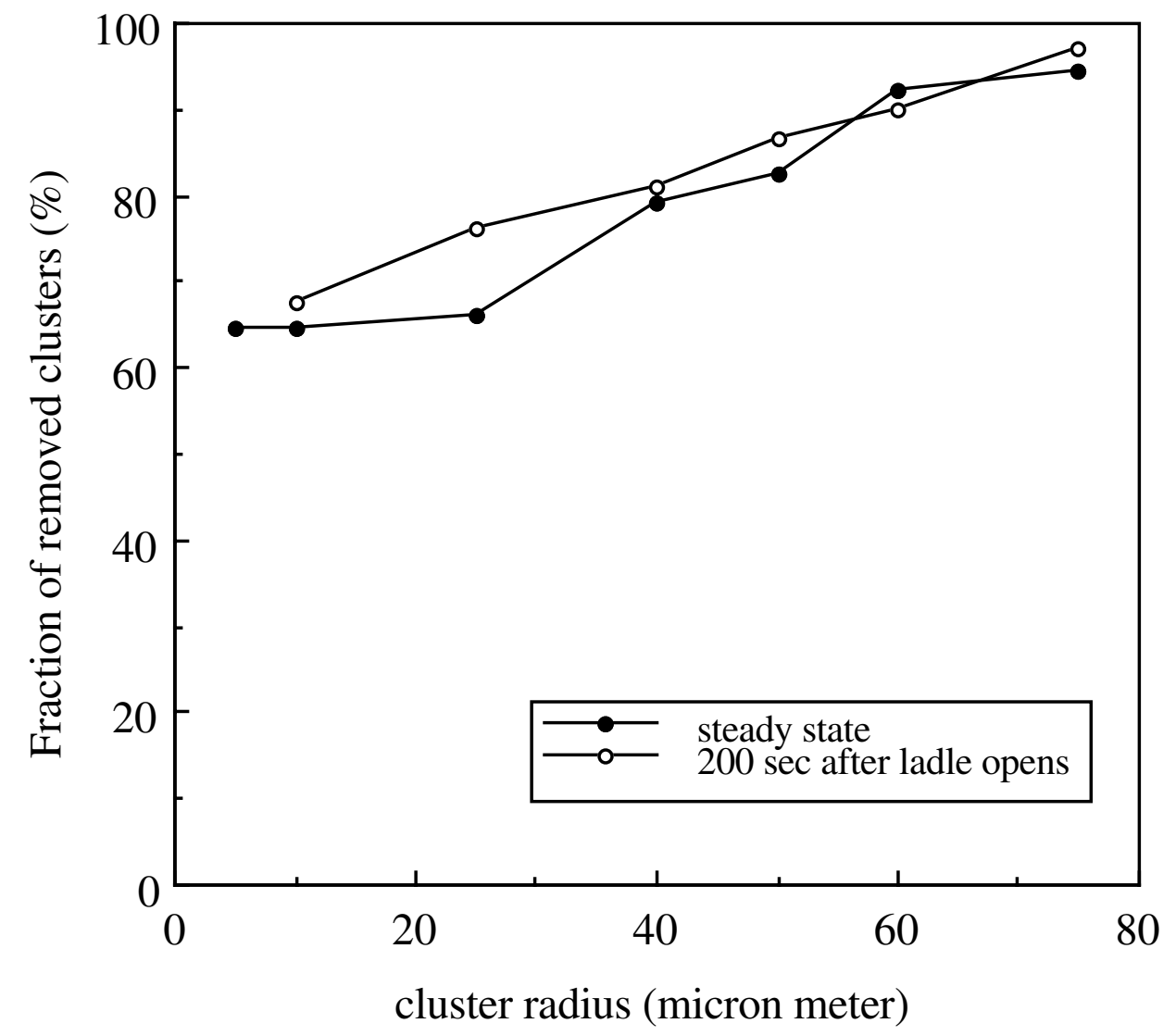

Figure 24 Comparison of clusters removed at steady state and at $200 \mathrm{sec}$ after new ladle opens. 


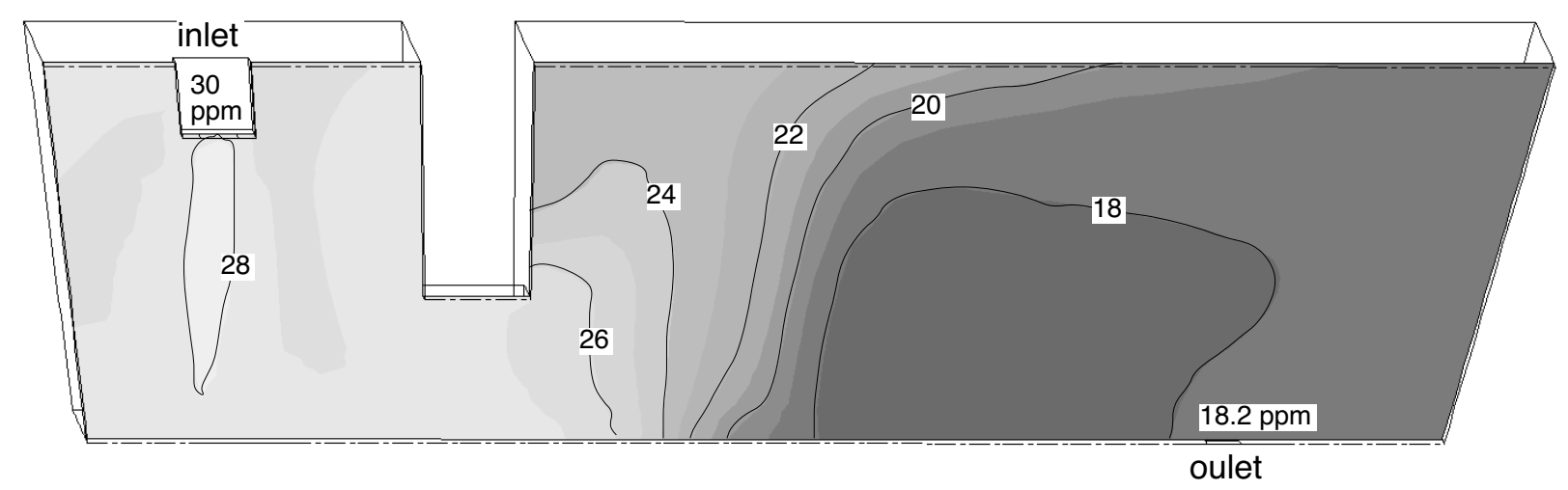

Figure $25 \mathrm{Al}_{2} \mathrm{O}_{3}$ concentration at $400 \mathrm{sec}$

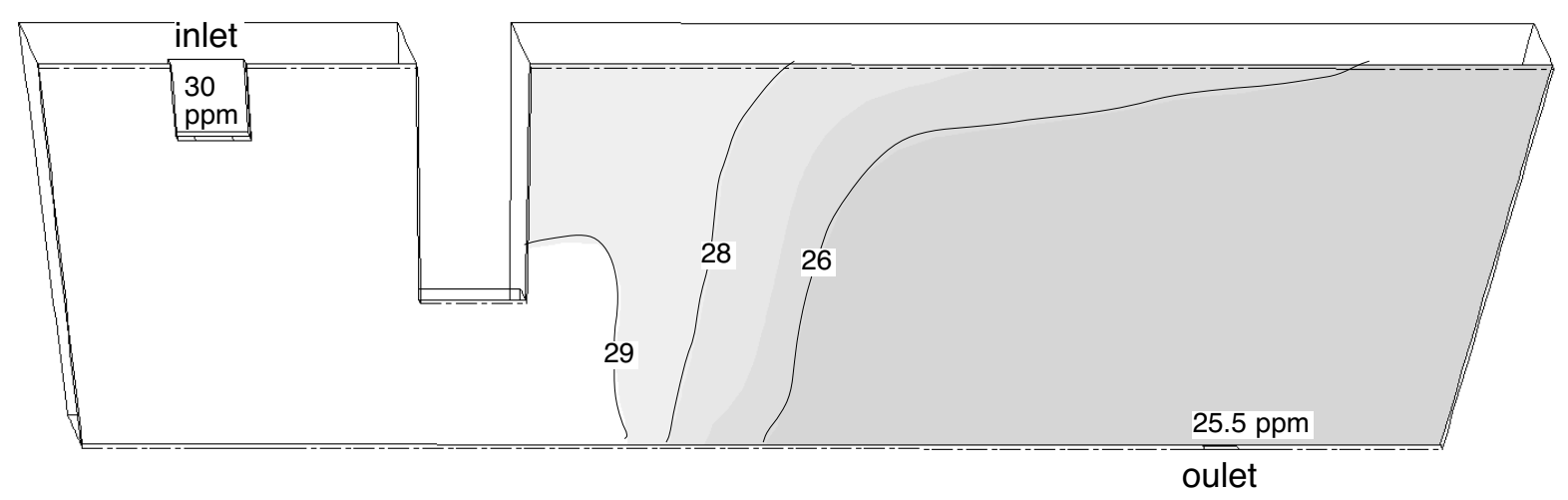

Figure $26 \mathrm{Al}_{2} \mathrm{O}_{3}$ concentration at $1,000 \mathrm{sec}$ 


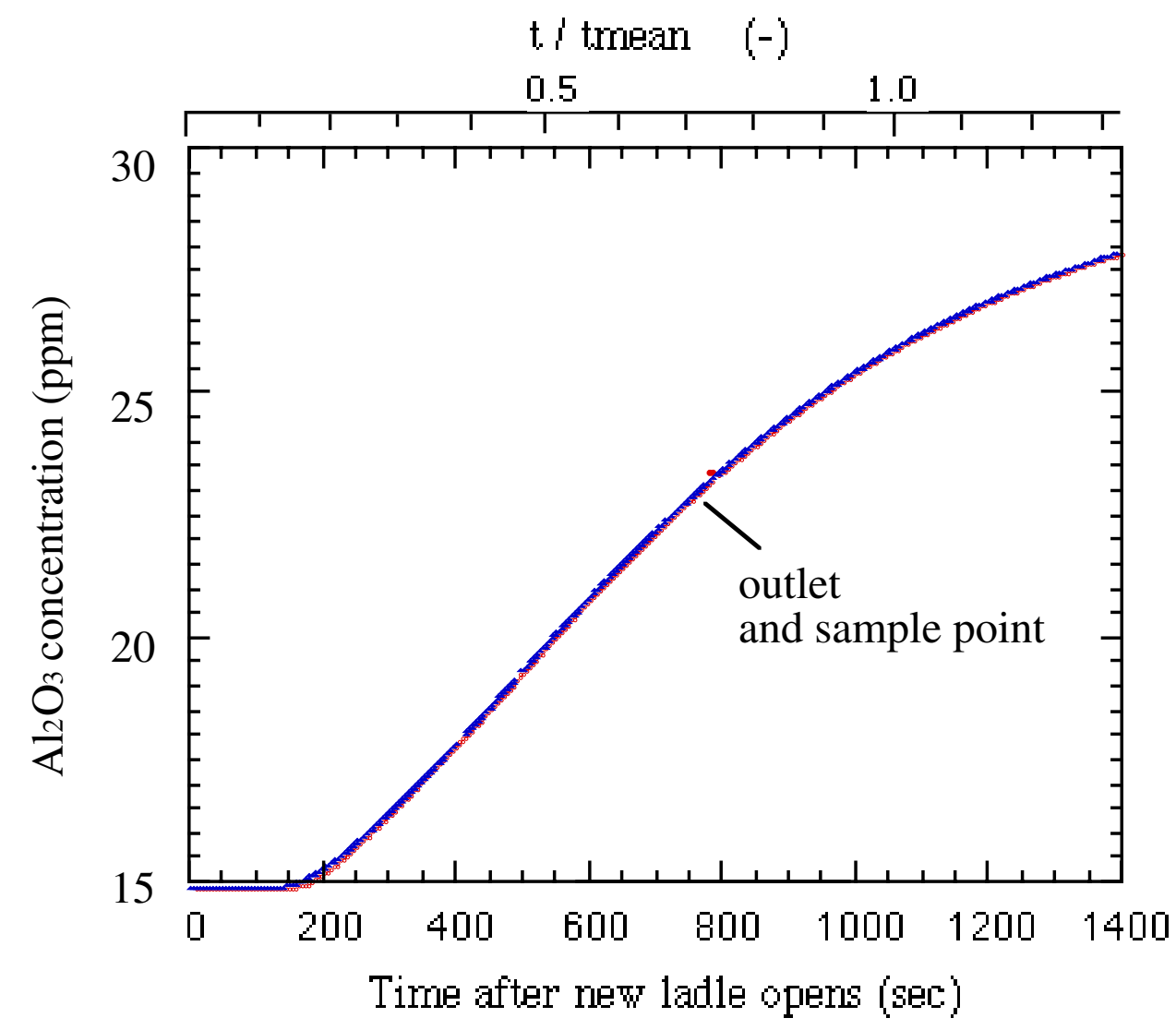

Figure 27 Evolution of $\mathrm{Al}_{2} \mathrm{O}_{3}$ concentration at sample position and at tundish outlet (scalar diffusion model) 


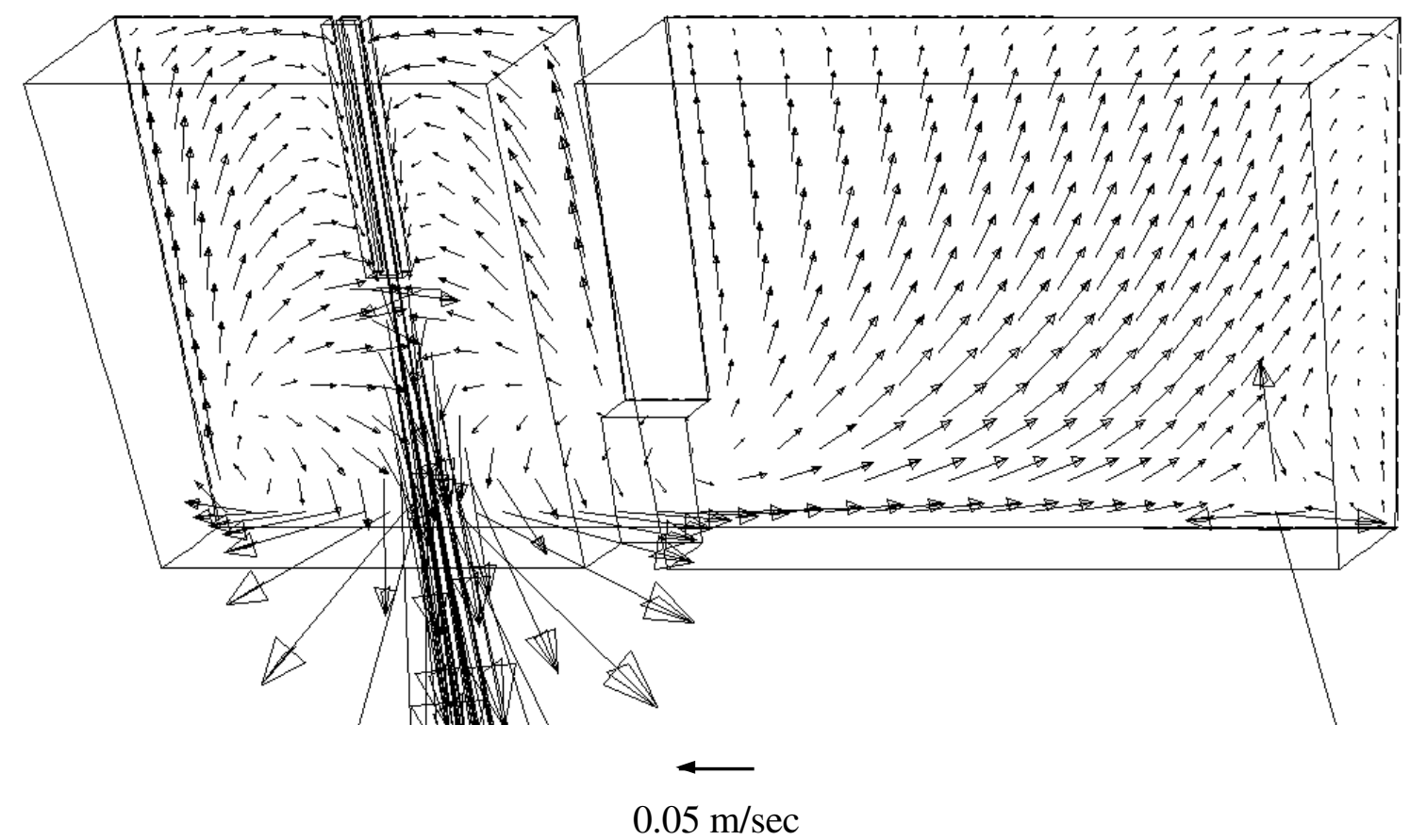

Figure 28 Calculated molten steel flow distribution at center plane (non-isothermal model with new geometry) 


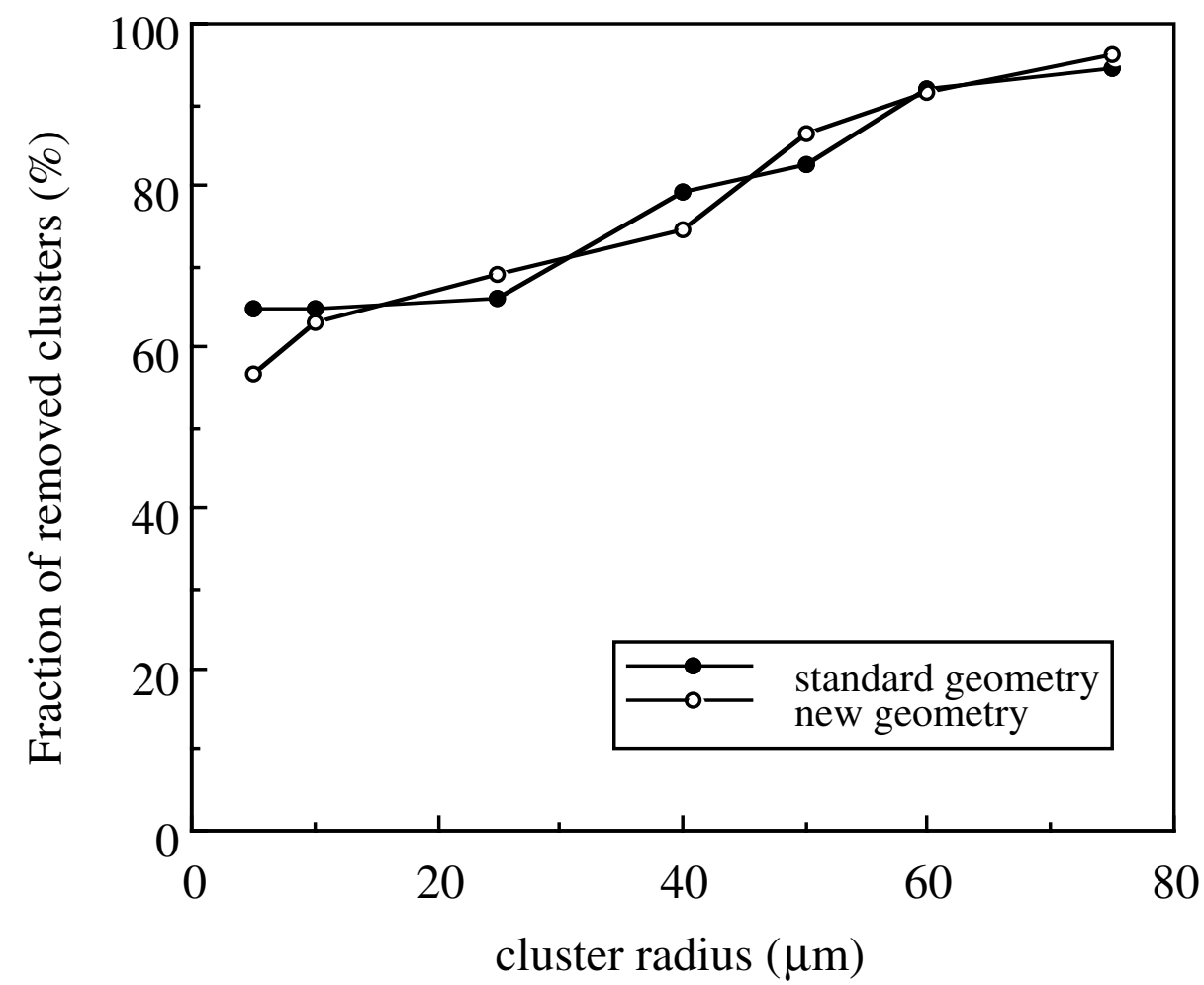

Figure 29 Comparison of fraction of removed clusters between standard and new tundish geometry (trajectory model based on Figure 6-8 flow). 


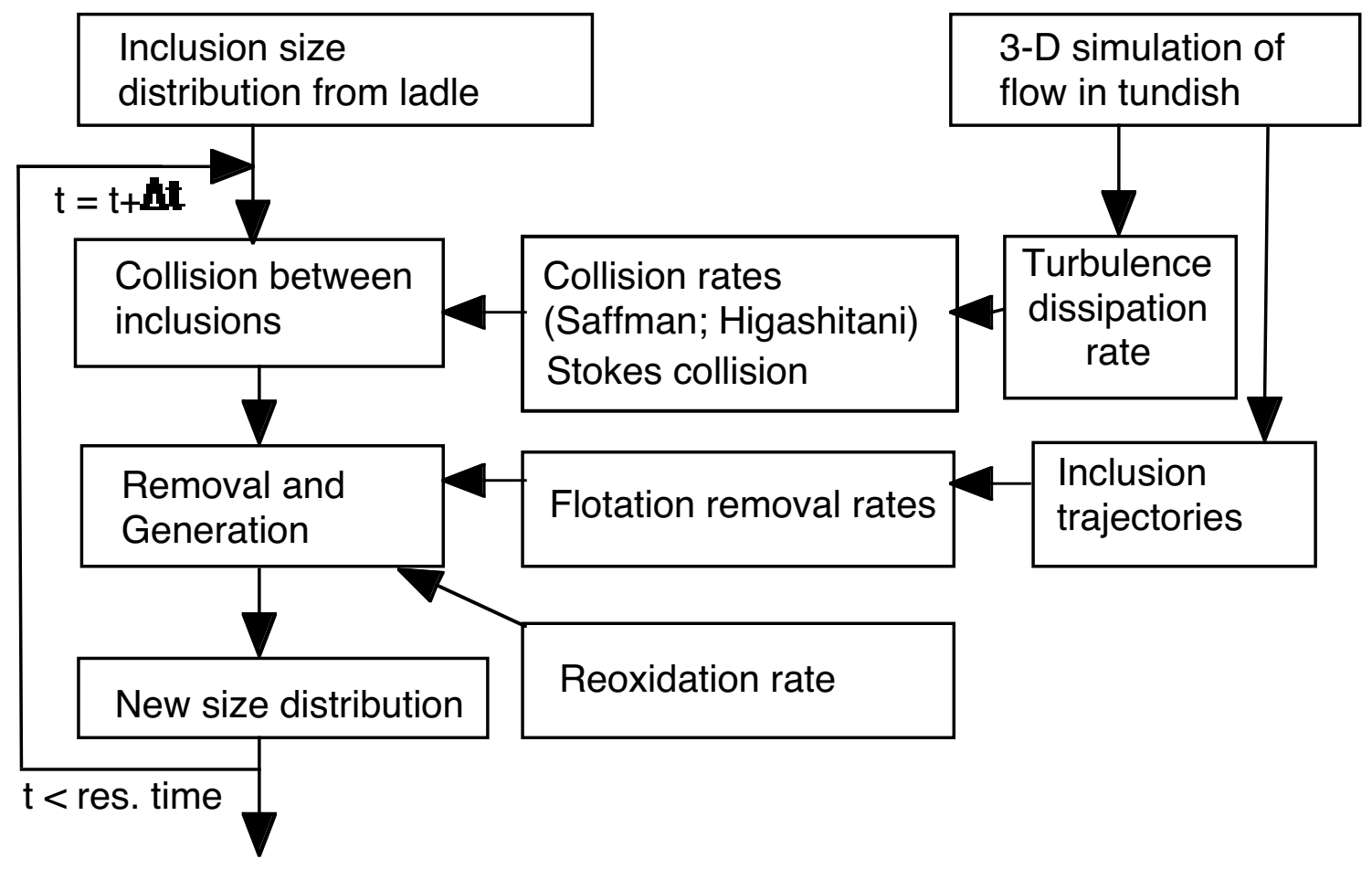

Figure 30 Inclusion size evolution model flow chart 